\title{
Experimental Investigation on Material Transfer Mechanism in WEDM of Pure Titanium (Grade-2)
}

\author{
Anish Kumar, ${ }^{1}$ Vinod Kumar, ${ }^{2}$ and Jatinder Kumar ${ }^{3}$ \\ ${ }^{1}$ Department of Mechanical Engineering, M.M.University, Mullana, Ambala, Haryana 133207, India \\ ${ }^{2}$ Department of Mechanical Engineering, Thapar University, Patiala, Punjab 147004, India \\ ${ }^{3}$ Department of Mechanical Engineering, National Institute of Technology, Kurukshetra, Haryana 136119, India
}

Correspondence should be addressed to Anish Kumar; anish_kaushik@rediffmail.com

Received 1 May 2013; Revised 7 October 2013; Accepted 9 October 2013

Academic Editor: Augusto Deus

Copyright (c) 2013 Anish Kumar et al. This is an open access article distributed under the Creative Commons Attribution License, which permits unrestricted use, distribution, and reproduction in any medium, provided the original work is properly cited.

This research work mainly focused on experimental investigation on material transfer mechanism in WEDM of pure titanium. The effects of machining parameters such as pulse on time, pulse off time, peak current, spark gap voltage, wire feed, and wire tension on the material removal rate (MRR), overcut, and surface roughness for pure titanium in WEDM process were explored. The selected machined samples were analyzed using energy dispersive X-ray analysis, scanning electron microscope, and X-ray diffraction techniques. It was observed from the results that a significant material transfer occurred from the dielectric, as well as tool, electrode on the work surface either in free form and/or in compound form. Also the multiresponse optimization of process parameters was done using desirability approach. The predictions from this model were validated by conducting experiments.

\section{Introduction}

The use of light, thin, and compact mechanical elements has recently become a global trend. The search for new, lightweight material with greater strength and toughness has led to the development of new generation of materials such as titanium. Having greater hardness and reinforcement strength, these materials are difficult to machine by the traditional methods. Although these materials can be machined conventionally, subsurface damages such as metallurgical alterations, work hardening, and microcracks can occur. Since the cost of using conventional machining is generally prohibitive, nonconventional machining such as wire electric discharge machining (WEDM) is the ideal technique in dealing with these materials [1]. Wire electrical discharge machining (WEDM) is a specialized thermal machining process capable of accurately machining parts with varying hardness or complex shapes, which have sharp edges that are very difficult to be machined by the main stream machining processes. This practical technology of the WEDM process is based on the conventional EDM sparking phenomenon utilizing the widely accepted noncontact technique of material removal. Since the introduction of the process, WEDM has evolved from a simple means of making tools and dies to the best alternative of producing microscale parts with the highest degree of dimensional accuracy and surface finish quality. Some of the common applications of WEDM are including the fabrication of the stamping and extrusion tools and dies, fixtures and gauges, prototypes, aircraft and medical parts, and grinding wheel form tools [2]. The material removal mechanism of WEDM is very similar to the conventional EDM process involving the erosion effect produced by the electrical discharges (sparks). In WEDM, material is eroded from the work piece by a series of discrete sparks occurring between the work piece and the wire, separated by a stream of dielectric fluid, which is continuously fed to the machining zone. In case of WEDM, a wire electrode is trailing vertically through the work piece which usually is fed horizontally. This process utilizes a continuously traveling wire electrode made of thin copper, brass, or tungsten of diameter $0.05-0.3 \mathrm{~mm}$, which is capable of achieving very small corner radii $[3,4]$. The wire is kept in tension using a mechanical tensioning device reducing the tendency of producing inaccurate parts. During the WEDM process, the material is eroded from the work piece by a series of discrete sparks, ahead of the wire. The microprocessor used to continuously feed thin wire will 
constantly maintain the gap ( 0.025 to 0.05$) \mathrm{mm}$ between the wire piece and the work piece. In WEDM process, there is no direct contact between the work piece and the wire piece thus eliminating the mechanical stresses during machining.

\section{Background of Research Work}

Miller et al. [5] presented a study for the optimization of cutting parameters which were effective for material removal rate and surface finish. The surface finish increased on with increasing the discharge current, pulse duration, and wire speed. Huang and Liao [6] studied the uses of grey relational and signal-to-noise ratio for demonstrating the influence of table feed and pulse on-time on the MRR. Hewidy et al. [7] modeled the machining parameters of wire electrical discharge machining of Inconel-601 using RSM. It was concluded that the volumetric metal removal rate generally increased with the increase of the peak current value and water pressure. Mahapatra and Patnaik [8] optimized the parameters using Taguchi method on D2 tool steel as work material in WEDM process. It was observed that discharge current, pulse duration, dielectric flow rate, and the interaction between discharge current and pulse duration were the most significant parameters for cutting operation. Mathematical models were developed for optimization of MRR and surface finish using nonlinear regression method. Ramakrishnan and Karunamoorthy [9] used Taguchi's robust design approach for WEDM. The three responses, namely, material removal rate, surface roughness, and wire wear ratio were considered. Manna and Bhattacharyya [10] optimized the machining parameters using the Taguchi and Gauss elimination method. The test results concluded that the voltage and pulse on time were the most significant parameters for controlling the metal removal rate. Sarkar et al. $[11,12]$ presented the modeling and optimization of wire electrical discharge machining of $\gamma$-TiAl in single and multipass cutting operation. A second-order mathematical model and ANN approach, in terms of machining parameters, were developed for cutting speed, surface roughness, and wire compensation using RSM. Yang et al. [13] analyzed the variations in metal removal rate, surface roughness average, and corner deviation (CD) of wire electrical discharge machining (WEDM) process in relation to the cutting of pure tungsten profiles. A hybrid method including response surface methodology (RSM) and back-propagation neural network (BPNN) integrated simulated annealing algorithm (SAA) was proposed to determine an optimal parameter setting. Kumar et al. [14] explored the study on WEDM in machining of commercially pure titanium (grade-2). The parameters such as pulse on time, pulse off time, peak current, spark gap set voltage, wire feed, and wire tension were varied to investigate their effects on the cutting rate, gap current, and surface roughness of the machined specimens. Shah et al. [15] investigated seven machining parameters in addition to varying material thickness on machining responses such as MRR, kerf, and surface roughness of tungsten carbide samples machined by WEDM. The design of experiments was based on Taguchi orthogonal designs. Results showed the little effect of material thickness on material removal rate and kerf. Sadeghi et al. [16] discussed effects of process parameters on surface roughness and metal removal rate in WEDM of AISI D5 steel alloy. It was found that discharge current and pulse interval were more significant for MRR and surface roughness than open circuit voltage. Kung and Chiang [17] studied behavior of wire electric discharge machining of aluminum oxide-based ceramics. The effects of machining parameters on material removal rate and surface roughness were evaluated. Tzeng et al. [18] analyzed the dependence of the material removal rate and workpiece surface finish on process parameters during the manufacture of pure tungsten profiles by wire electrical discharge machining (WEDM). A hybrid method including a back-propagation neural network (BPNN), a genetic algorithm (GA), and response surface methodology (RSM) was proposed to determine optimal parameter settings of the WEDM process. The results showed that the RSM and BPNN/GA methods were both effective tools for the optimization of WEDM process parameters. Rao and Pawar [19] proposed the mathematical models using response surface modeling (RSM) for correlating the interrelationships of various WEDM parameters such as pulse on time, pulse off time, peak current, and servo feed setting on the machining speed and surface roughness. Yu et al. [20] explored the study on polycrystalline silicon material using WEDM process to optimize the groove width, surface roughness, and cutting speed. The results showed that pulse on time was the most significant factor for cutting speed, surface roughness, and groove width. Kuruvila and Ravindra [21] investigated the WEDM machining parameters on the hot die steel for dimensional error, surface roughness, and MRR. The study revealed that smaller pulse off time and pulse on time resulted in improving the overall performance with minimum dimensional error and good surface finish. The present study explores the machinability of pure titanium (grade-2) using WEDM process. The pure titanium (grade-2) is extensively used for sea water piping's, reactor vessels, and heat exchangers. The six parameters, that is, pulse on time, pulse off time, peak current, spark gap voltage, wire feed, and wire tension, were varied to investigate their effects on output responses, that is, MRR, overcut, and surface roughness. In addition, a second order mathematical model, in terms of machining parameters, was developed using response surface methodology. These responses were optimized using multiresponse optimization through desirability. The ANOVA was used to identify the significance of the process parameters involved during machining. The test results confirmed the validity and adequacy of the developed RSM model. The selected machined samples were analyzed using energy dispersive X-ray analysis, scanning electron microscope, and X-ray diffraction techniques.

\section{Materials and Methods}

The experiments were performed on a four-axis CNC type WEDM (Electronica Sprintcut, 734) as shown in Figure 1(a). The six parameters, that is, pulse on time, pulse off time, peak current, spark gap voltage, wire feed, and wire tension were varied to investigate their effect on output responses that is, the MRR, overcut, and surface roughness. The parameters kept constant during machining were electrode 


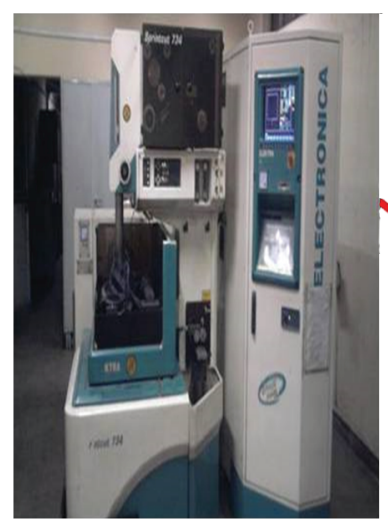

(a)

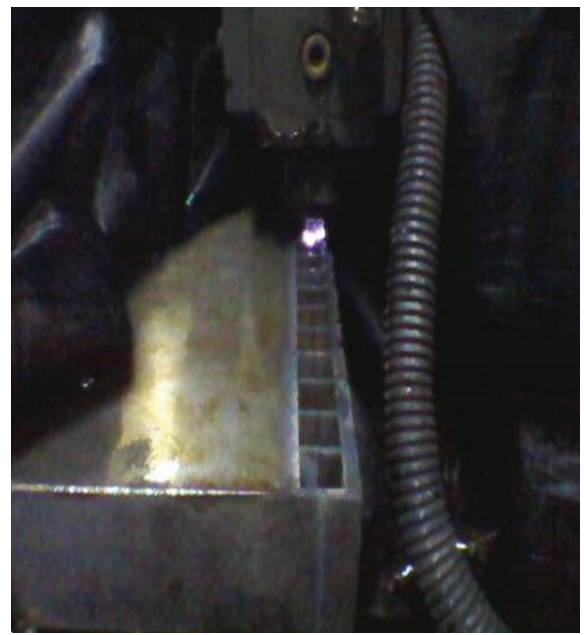

(d)

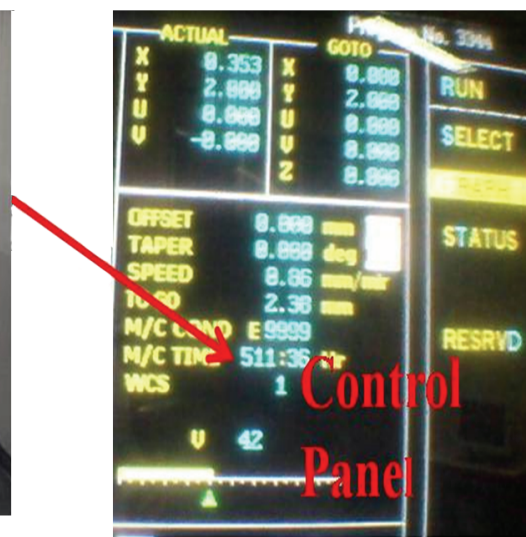

(b)

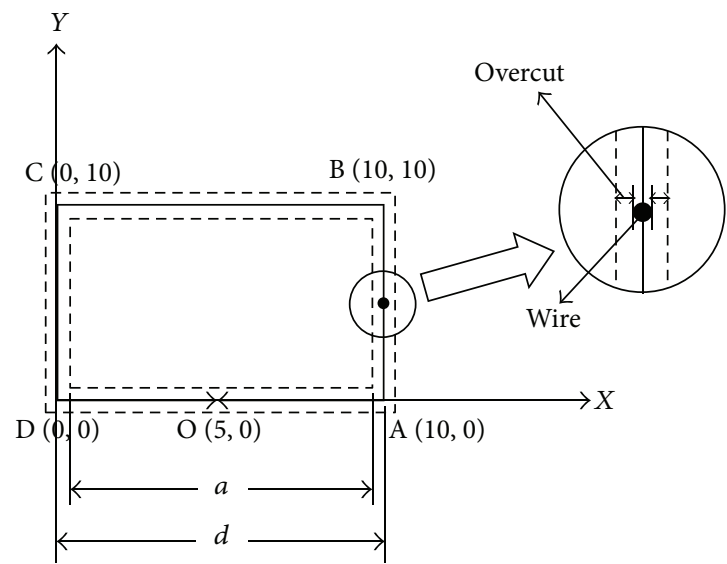

(c)

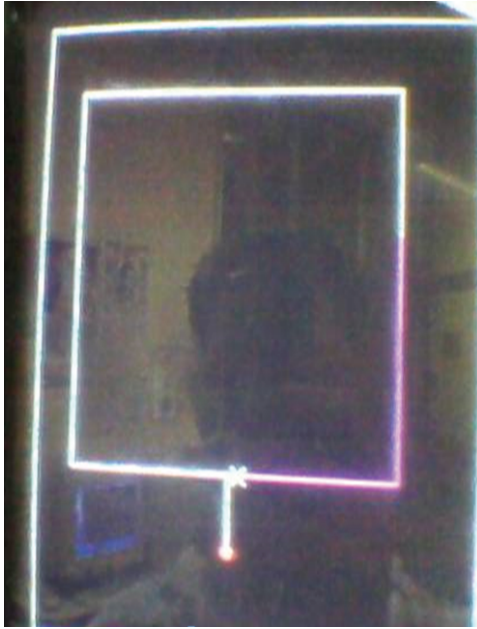

(e)

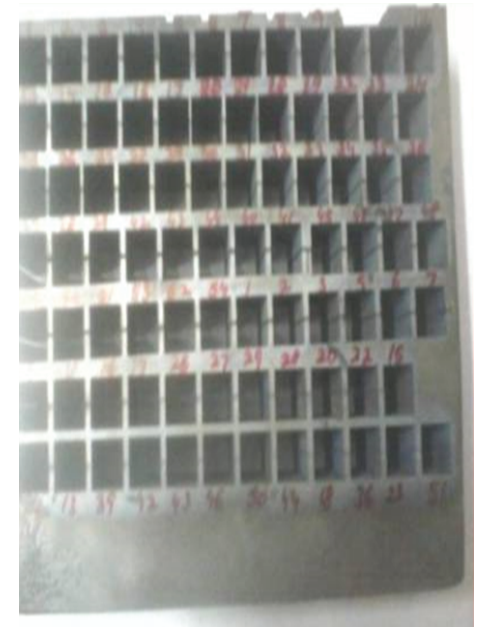

(f)

FIGURE 1: Job profile and experimental setup of WEDM machine tool (a) 4-axis WEDM CNC type, machine tool, (b) machine control panel, (c) work-path profile, (d) wire (tool) and workpiece (e) wire path on control panel, (f) square punch produced after WEDM.

(brass wire with $\emptyset 0.25 \mathrm{~mm}$ ), thickness of material $26 \mathrm{~mm}$, and dielectric pressure $7 \mathrm{~kg} / \mathrm{cm}^{2}$. The chemical composition of work material taken for experimentation was C: $0.10 \%, \mathrm{~N}$ : $0.03 \%, \mathrm{O}_{2}: 0.25 \%, \mathrm{H}_{2}: 0.015 \%$, Fe: $0.30 \%$, and Ti: $99.03 \%$. The work material in the form of square plate having dimensions $148 \mathrm{~mm} \times 148 \mathrm{~mm} \times 26 \mathrm{~mm}$ was taken for the experimentation work. The surface roughness of machined surface was measured in $\mu \mathrm{m}$. The measurements were taken three times using the Mitutoyo's SURFTEST (SJ-301). Figures 1(b)-1(d) show the work and wire path profiles during machining. The reference point taken was $\mathrm{O}(5,0)$, and the wire tool traces the path OA-AB-BC-CD-DO. The CNC program for machining was generated using ELAPT software.

\section{Design of Experiment}

The process parameters and their levels for the main experiments were decided on the basis of the pilot experiments conducted using one factor at a time approach (OFTA) [14]. The main experiments were performed using RSM based Box-Behnken design including pulse on time, pulse off time, peak current, spark gap voltage, wire feed, and wire tension machine parameters as shown in Table 1. In the present study, an attempt has been made to develop empirical models using statistical regression analysis. It provides a relationship between the input process parameters and output performance based on experimental results. Finally, the analysis was done to study the main effects and their interactions to explore the quadratic effect of parameters on the performance. The polynomial as the quadratic model relating the response to the factors for Box-Behnken design is given as

$$
Y=\beta_{0}+\sum_{i=1}^{K} \beta_{i} x_{i}+\sum_{i=1}^{k} \beta_{i i} x_{i}^{2}+\sum_{i<j} \beta_{i j} x_{i} x_{j}
$$

where $Y$ is the desired response and $x_{i}(1,2, k)$ are the independent of $k$ quantitative process variables. $\beta_{0}$ is constant, and $\beta_{i}, \beta_{i i}$, and $\beta_{i j}$ are the coefficients of linear, quadratic, and cross-product terms. 
TABLE 1: Factors and their levels.

\begin{tabular}{|c|c|c|c|c|c|c|}
\hline \multirow{2}{*}{ S. no. } & \multirow{2}{*}{ Symbols } & \multirow{2}{*}{ Input factors } & \multicolumn{3}{|c|}{ Level } & \multirow{2}{*}{ Units } \\
\hline & & & I & II & III & \\
\hline 1 & $A$ & Pulse on time & 0.7 & 0.9 & 1.1 & $\mu \mathrm{s}$ \\
\hline 2 & $B$ & Pulse off time & 17 & 26 & 38 & $\mu \mathrm{s}$ \\
\hline 3 & C & Peak current & 120 & 160 & 200 & Ampere \\
\hline 4 & $D$ & Spark gap voltage & 40 & 50 & 60 & Volt \\
\hline 5 & $E$ & Wire feed & 4 & 7 & 10 & $\mathrm{~m} / \mathrm{min}$ \\
\hline 6 & $F$ & Wire tension & 500 & 950 & 1400 & Grams \\
\hline
\end{tabular}

4.1. Response Surface Methodology. Response surface methodology is a collection of mathematical and statistical techniques for empirical model building. The RSM was applied for modeling of output responses such as material removal rate, overcut, and surface roughness. The general second-order model is defined as

$$
Y=f(A, B, C, D, E, F)
$$

where $Y$ is the desired response and $f$ is the response function. For the analysis purpose, the approximation of $Y$ was proposed using the fitted second order polynomial regression model.

\section{Results and Discussion}

5.1. Effect of Process Parameters on Material Removal Rate. Consider

$$
\operatorname{MRR}=C_{S} \times b \times t \mathrm{~mm}^{3} / \mathrm{min},
$$

where $C_{S}=$ cutting speed in $\mathrm{mm} / \mathrm{min}$ (taken from the machine control panel as shown in Figure 1(b)), $b=$ width of cut in $(10 \mathrm{~mm})$, and $t=$ thickness of work piece in $(26 \mathrm{~mm})$. The effect of the process parameters on the MRR has been determined by computing the values as shown in Table 2 using Design expert 6.0, software. The adequacy of model and effects of process parameters with their interactions for MRR are shown in ANOVA (Table 3). This model was developed at 95\% confidence level. The model $F$ value of 97.91 implied that the model is significant for MRR. It was observed from the $F$ and $P$ values that the factors $A$ (pulse on time) and $B$ (pulse off time) have a most significant effect on MRR. The values of "Prob. > F" less than 0.05 indicate that the model terms are significant. In this case $A, B, C, D, B C, B D, B^{2}$, and $C^{2}$ were significant model terms. The lack of fit $F$ value of 0.4750 implies that it is not significant compared to pure error. The "Pred. $R$-squared" of 0.9228 is in reasonable agreement with the "Adj. $R$-squared" of 0.9360 . The model for MRR is given by

$$
\begin{aligned}
\text { MRR }= & 22.08597+10.23958 \times \text { Pulse on Time } \\
& -1.00948 \times \text { Pulse off Time } \\
& -0.070586 \times \text { Peak Current } \\
& -0.17842 \times \text { Spark Gap Voltage }
\end{aligned}
$$

$$
\begin{aligned}
& +0.00854025 \times \text { Pulse off Time }{ }^{2} \\
& +0.000172852 \times \text { Peak Current } \\
& +0.00126488 \times \text { Pulse off Time } \\
& \times \text { Peak Current }+0.00425 \\
& \times \text { Pulse off Time } \times \text { Spark Gap Voltage }
\end{aligned}
$$

Figures 2(a) and 2(b) show the three-dimensional interaction plots for the response MRR. From Figure 2(a), it was observed that MRR increased from $4.91 \mathrm{~mm}^{3} / \mathrm{min}$ to $7.70 \mathrm{~mm}^{3} / \mathrm{min}$ with the increase in peak current from 120 to $200 \mathrm{amp}$ and decrease of pulse off time from 38 to $17 \mu \mathrm{s}$. This result was concluded due to increase in peak current and decrease of pulse off time; the rate of discharge energy increases and pulse frequency decreases in wire electrodework gap. The concentration of discharge energy in the spark gap leads to melting and vaporization of molten metal and floating metal suspended in the electrical discharge which leads to increase of MRR. High peak current and low pulse off time increased the debris in the spark gap, which leads to abnormal arcing. The abnormal arcing decreased discharge rate and the material removal rate [22]. Also abnormal arcing reduced the dielectric strength resulting in wire breakage. It was observed from Figure 2 (b) that MRR increasing from $6.81 \mathrm{~mm}^{3} / \mathrm{min}$ to $8.93 \mathrm{~mm}^{3} / \mathrm{min}$ with the decrease of pulse off time 38 to $17 \mu \mathrm{s}$ and spark gap voltage 60 to $40 \mathrm{~V}$. This may reduce the gap between the work and wire electrodes during the spark. It was found that on decreasing the spark gap voltage, the wire speed increases which leads to increase the MRR. The present study revealed that higher MRR can be achieved at the lowest spark gap voltage, pulse off time, and high peak current. It was observed that WEDM surface produces the more irregular topography and defects included globules of debris, spherical particles, varying size craters, pockmarks, and microcracks as shown in Figures 5 and 6. An increase in discharge heat energy a pool of molten metal is formed and is overheated. The overheated molten metal evaporates forming gas bubbles that explode when the discharge ceases, taking molten metal material away. The result is the formation of crater. When the discharge ceases, these small gas bubbles will collapse containing lower pressure energy. The result is finer pockmarks, which also decrease the surface roughness. The spherical shape particles were reported due to surface tension of molten material. From the 
TABle 2: Design of experiments matrix and results.

\begin{tabular}{|c|c|c|c|c|c|c|c|c|c|}
\hline \multirow[b]{2}{*}{$\begin{array}{l}\text { Standard } \\
\text { run no. }\end{array}$} & \multirow[b]{2}{*}{$\begin{array}{c}\text { Pulse on } \\
\text { time } T_{\text {on }} \\
(\mu \mathrm{s})\end{array}$} & \multicolumn{3}{|c|}{ Factors } & \multirow[b]{2}{*}{$\begin{array}{c}\text { Wire feed } \\
\text { WF }(\mathrm{m} / \mathrm{min})\end{array}$} & \multirow[b]{2}{*}{$\begin{array}{l}\text { Wire tension } \\
\text { WT (grams) }\end{array}$} & \multicolumn{3}{|c|}{ Response variables } \\
\hline & & $\begin{array}{c}\text { Pulse off } \\
\text { time } T_{\text {off }} \\
\quad(\mu \mathrm{s})\end{array}$ & $\begin{array}{l}\text { Peak current } \\
\text { Ip (Ampere) }\end{array}$ & $\begin{array}{c}\text { Spark gap } \\
\text { voltage SV } \\
\text { (Volt) }\end{array}$ & & & $\begin{array}{c}\text { MRR } \\
\left(\mathrm{mm}^{3} / \mathrm{min}\right)\end{array}$ & $\begin{array}{l}\text { Overcut } \\
(\mu \mathrm{m})\end{array}$ & $\begin{array}{c}\text { Surface } \\
\text { roughness } \\
(\mu \mathrm{m})\end{array}$ \\
\hline 1 & 1.1 & 28 & 200 & 50 & 7 & 500 & 9.6 & 40 & 3.22 \\
\hline 2 & 0.9 & 38 & 160 & 50 & 4 & 500 & 4.92 & 26 & 2.48 \\
\hline 3 & 0.7 & 28 & 160 & 60 & 4 & 950 & 3.39 & 22 & 2.23 \\
\hline 4 & 0.9 & 17 & 120 & 50 & 10 & 950 & 8.29 & 38 & 2.75 \\
\hline 5 & 0.9 & 28 & 120 & 60 & 7 & 500 & 4.45 & 31 & 2.47 \\
\hline 6 & 1.1 & 28 & 160 & 40 & 4 & 950 & 9.2 & 33 & 2.93 \\
\hline 7 & 0.9 & 38 & 160 & 50 & 10 & 1400 & 4.77 & 25 & 2.48 \\
\hline 8 & 0.9 & 28 & 160 & 50 & 7 & 950 & 5.19 & 30 & 2.65 \\
\hline 9 & 0.9 & 17 & 160 & 50 & 4 & 500 & 8.81 & 33 & 2.81 \\
\hline 10 & 1.1 & 28 & 160 & 40 & 10 & 950 & 8.59 & 33 & 2.94 \\
\hline 11 & 1.1 & 38 & 160 & 40 & 7 & 950 & 8.3 & 32 & 2.91 \\
\hline 12 & 1.1 & 28 & 160 & 60 & 4 & 950 & 7.03 & 35 & 2.83 \\
\hline 13 & 0.9 & 17 & 160 & 50 & 10 & 500 & 8.19 & 32 & 2.79 \\
\hline 14 & 0.9 & 28 & 160 & 50 & 7 & 950 & 4.67 & 30 & 2.61 \\
\hline 15 & 0.7 & 28 & 120 & 50 & 7 & 500 & 3.28 & 25 & 2.49 \\
\hline 16 & 0.9 & 28 & 160 & 50 & 7 & 950 & 5.51 & 31 & 2.68 \\
\hline 17 & 0.9 & 28 & 120 & 60 & 7 & 1400 & 4.66 & 28 & 2.49 \\
\hline 18 & 0.7 & 38 & 160 & 40 & 7 & 950 & 3.65 & 28 & 2.32 \\
\hline 19 & 0.9 & 38 & 120 & 50 & 10 & 950 & 4.37 & 26 & 2.31 \\
\hline 20 & 0.9 & 28 & 200 & 40 & 7 & 1400 & 6.72 & 38 & 2.89 \\
\hline 21 & 0.9 & 28 & 200 & 60 & 7 & 500 & 6.67 & 32 & 2.69 \\
\hline 22 & 0.9 & 38 & 200 & 50 & 10 & 950 & 6.54 & 35 & 2.57 \\
\hline 23 & 0.9 & 28 & 120 & 40 & 7 & 1400 & 5.07 & 29 & 2.71 \\
\hline 24 & 0.7 & 28 & 120 & 50 & 7 & 1400 & 3.3 & 24 & 2.51 \\
\hline 25 & 0.9 & 38 & 200 & 50 & 4 & 950 & 7.07 & 35 & 2.56 \\
\hline 26 & 1.1 & 28 & 160 & 60 & 10 & 950 & 6.77 & 37 & 2.82 \\
\hline 27 & 1.1 & 28 & 120 & 50 & 7 & 500 & 7.1 & 33 & 2.77 \\
\hline 28 & 0.7 & 28 & 160 & 40 & 10 & 950 & 4.27 & 30 & 2.35 \\
\hline 29 & 0.7 & 28 & 200 & 50 & 7 & 500 & 4.49 & 31 & 2.48 \\
\hline 30 & 0.7 & 17 & 160 & 40 & 7 & 950 & 6.9 & 33 & 2.70 \\
\hline 31 & 0.7 & 28 & 200 & 50 & 7 & 1400 & 4.44 & 33 & 2.51 \\
\hline 32 & 0.9 & 28 & 160 & 50 & 7 & 950 & 4.7 & 31 & 2.65 \\
\hline 33 & 0.9 & 17 & 200 & 50 & 4 & 950 & 8.06 & 42 & 2.88 \\
\hline 34 & 0.9 & 28 & 160 & 50 & 7 & 950 & 5.61 & 33 & 2.65 \\
\hline 35 & 1.1 & 17 & 160 & 40 & 7 & 950 & 11.16 & 43 & 3.28 \\
\hline 36 & 0.9 & 17 & 200 & 50 & 10 & 950 & 8.28 & 37 & 2.98 \\
\hline 37 & 0.9 & 28 & 200 & 40 & 7 & 500 & 7.07 & 35 & 2.84 \\
\hline 38 & 0.7 & 28 & 160 & 40 & 4 & 950 & 4.41 & 30 & 2.33 \\
\hline 39 & 0.9 & 38 & 160 & 50 & 10 & 500 & 4.96 & 25 & 2.50 \\
\hline 40 & 0.9 & 28 & 160 & 50 & 7 & 950 & 5.65 & 32 & 2.69 \\
\hline 41 & 1.1 & 38 & 160 & 60 & 7 & 950 & 6.77 & 33 & 2.66 \\
\hline 42 & 0.7 & 17 & 160 & 60 & 7 & 950 & 4.14 & 30 & 2.60 \\
\hline 43 & 0.9 & 28 & 200 & 60 & 7 & 1400 & 6.57 & 32 & 2.68 \\
\hline 44 & 0.9 & 17 & 120 & 50 & 4 & 950 & 7.61 & 35 & 2.75 \\
\hline
\end{tabular}


TABle 2: Continued.

\begin{tabular}{|c|c|c|c|c|c|c|c|c|c|}
\hline \multirow[b]{2}{*}{$\begin{array}{l}\text { Standard } \\
\text { run no. }\end{array}$} & \multirow[b]{2}{*}{$\begin{array}{l}\text { Pulse on } \\
\text { time } T_{\text {on }} \\
(\mu \mathrm{s})\end{array}$} & \multicolumn{3}{|c|}{ Factors } & \multirow[b]{2}{*}{$\begin{array}{c}\text { Wire feed } \\
\text { WF (m/min) }\end{array}$} & \multirow[b]{2}{*}{$\begin{array}{l}\text { Wire tension } \\
\text { WT (grams) }\end{array}$} & \multicolumn{3}{|c|}{ Response variables } \\
\hline & & $\begin{array}{c}\text { Pulse off } \\
\text { time } T_{\text {off }} \\
(\mu \mathrm{s})\end{array}$ & $\begin{array}{l}\text { Peak current } \\
\text { Ip (Ampere) }\end{array}$ & $\begin{array}{c}\text { Spark gap } \\
\text { voltage SV } \\
(\text { Volt })\end{array}$ & & & $\begin{array}{c}\text { MRR } \\
\left(\mathrm{mm}^{3} / \mathrm{min}\right)\end{array}$ & $\begin{array}{l}\text { Overcut } \\
(\mu \mathrm{m})\end{array}$ & $\begin{array}{c}\text { Surface } \\
\text { roughness } \\
(\mu \mathrm{m})\end{array}$ \\
\hline 45 & 0.7 & 28 & 160 & 60 & 10 & 950 & 3.75 & 25 & 2.28 \\
\hline 46 & 1.1 & 28 & 120 & 50 & 7 & 1400 & 7.11 & 35 & 2.75 \\
\hline 47 & 0.7 & 38 & 160 & 60 & 7 & 950 & 3.28 & 24 & 2.15 \\
\hline 48 & 0.9 & 17 & 160 & 50 & 4 & 1400 & 8.15 & 31 & 2.85 \\
\hline 49 & 0.9 & 28 & 120 & 40 & 7 & 500 & 5.36 & 31 & 2.78 \\
\hline 50 & 1.1 & 17 & 160 & 60 & 7 & 950 & 8.45 & 40 & 3.00 \\
\hline 51 & 0.9 & 38 & 120 & 50 & 4 & 950 & 4.55 & 25 & 2.29 \\
\hline 52 & 1.1 & 28 & 200 & 50 & 7 & 1400 & 8.37 & 35 & 3.12 \\
\hline 53 & 0.9 & 17 & 160 & 50 & 10 & 1400 & 7.53 & 37 & 2.82 \\
\hline 54 & 0.9 & 38 & 160 & 50 & 4 & 1400 & 4.92 & 25 & 2.49 \\
\hline
\end{tabular}

TABLE 3: The analysis of variance for main and interaction effects of parameters on MRR.

\begin{tabular}{|c|c|c|c|c|c|c|c|}
\hline Source & SS & DOF & MS & $F$-value & Prob. $>F$ & At $95 \%$ CI & \% Contribution \\
\hline Model & 180.93 & 8 & 22.62 & 97.91 & $<0.0001$ & significant & \\
\hline Pulse on time & 100.66 & 1 & 100.66 & 435.74 & $<0.0001$ & significant & 52.61 \\
\hline Pulse off time & 41.27 & 1 & 41.27 & 178.64 & $<0.0001$ & significant & 21.57 \\
\hline Peak current & 14.62 & 1 & 14.62 & 63.28 & $<0.0001$ & significant & 7.64 \\
\hline Spark gap voltage & 9.09 & 1 & 9.09 & 39.35 & $<0.0001$ & significant & 4.75 \\
\hline Pulse off time ${ }^{2}$ & 11.35 & 1 & 11.35 & 49.12 & $<0.0001$ & significant & 5.93 \\
\hline Peak current ${ }^{2}$ & 0.98 & 1 & 0.98 & 4.24 & 0.0453 & significant & 0.512 \\
\hline Pulse off time $\times$ peak current & 2.26 & 1 & 2.26 & 9.77 & 0.0031 & significant & 1.18 \\
\hline Lack of fit & 9.40 & 40 & 0.24 & 1.18 & 0.4750 & not significant & \\
\hline \multicolumn{8}{|l|}{$R^{2}=0.9457$} \\
\hline \multicolumn{8}{|l|}{$R^{2}$ adjusted $=0.9360$} \\
\hline Predicted $R^{2}=0.9228$ & & & & & & & \\
\hline
\end{tabular}

SS: sum of square, DOF: degree of freedom, MS: mean square, F-value: Fisher value.

previous studies, some of the molten material was not flushed away from the gap by dielectric fluid and remained in the electrical discharge. This material resolidifies on the surface of machined samples, that is known as recast layer [23]. Appearance of significant recast layer as shown in Figure 8. Figures 2(c) and 2(d) present the normal probability plot of residuals and residual versus predicted plots for MRR. It was observed that the residuals following a straight line concluding that the errors are normally distributed. Based on experimental results as shown in Table 2, maximum MRR = $11.16 \mathrm{~mm}^{3} / \mathrm{min}$ was obtained when the parameters were set at pulse on time $=1.1 \mu \mathrm{s}$, pulse off time $=17 \mu \mathrm{s}$, peak current $=$ $160 \mathrm{~A}$, spark gap voltage $=40 \mathrm{~V}$, wire feed $=7 \mathrm{~m} / \mathrm{min}$, and wire tension $=950$ grams.

5.2. Effect of Process Parameters on the Overcut. The profile traced by wire and the job are not the same. The perpendicular distance between the actual profile and the profile traced by the wire is equal to half of the width of the cut. Thus, the actual job produced is either undersized or oversized depending upon whether the job is punch or die. In the present study, the job has been considered as a square punch as shown in Figure 1(f). The dimensional deviation of square punch is equal to the half the width of the cut. The dimensional deviation is measured using a digimatic caliper (Mitutoyo) having least count $0.001 \mathrm{~mm}$. The overcut as shown in (Figure 1(c)) was determined as

$$
\begin{aligned}
& \operatorname{Overcut}(\delta)= \text { dimensional deviation }(D)-0.5 \\
& \times \text { wire diameter }(d) \\
&(D)=0.5\left(W_{P}-W_{a}\right)
\end{aligned}
$$

where $W_{P}=$ programmed path and $W_{a}=$ actual job profile. The ANOVA and $F$-ratio test were performed to verify the adequacy of model. The model $F$ value of 30.71 in Table 4 implied that the model is significant for overcut. There is only a $0.01 \%$ chance that the "model $F$ value" could have largely occurred due to noise. The $P$ value of this factor is $99 \%$, which shows its strong influence with a contribution of $30.07 \%$ and $28.76 \%$. The values of "Prob. $>F$ " less than 0.05 indicate that the model terms are significant. In this case $A, B, C, D$, 


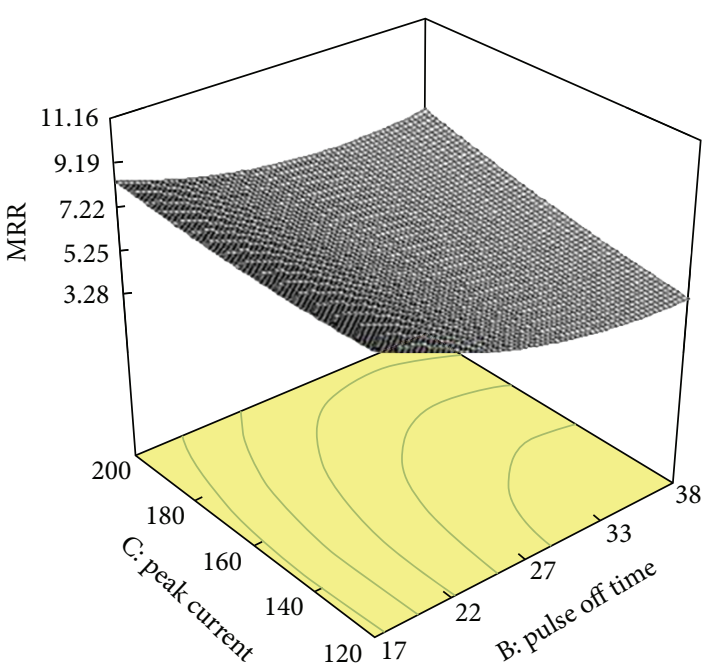

(a)

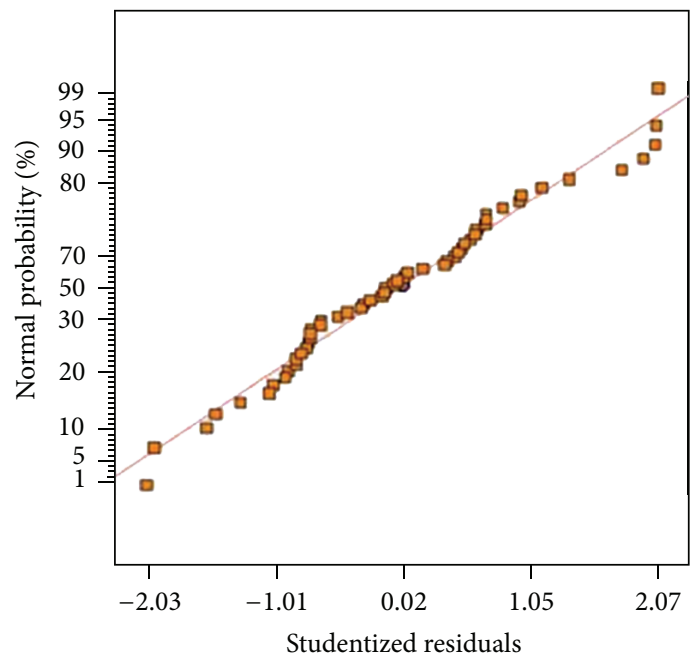

(c)

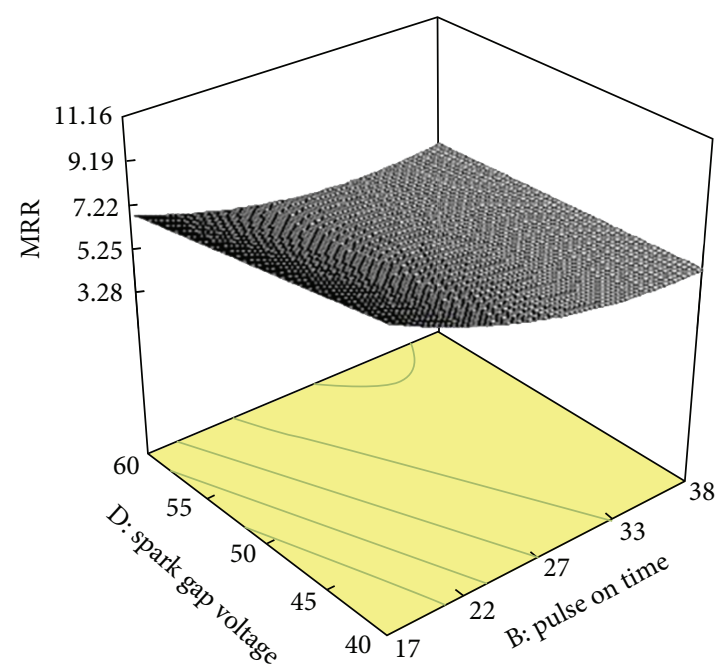

(b)

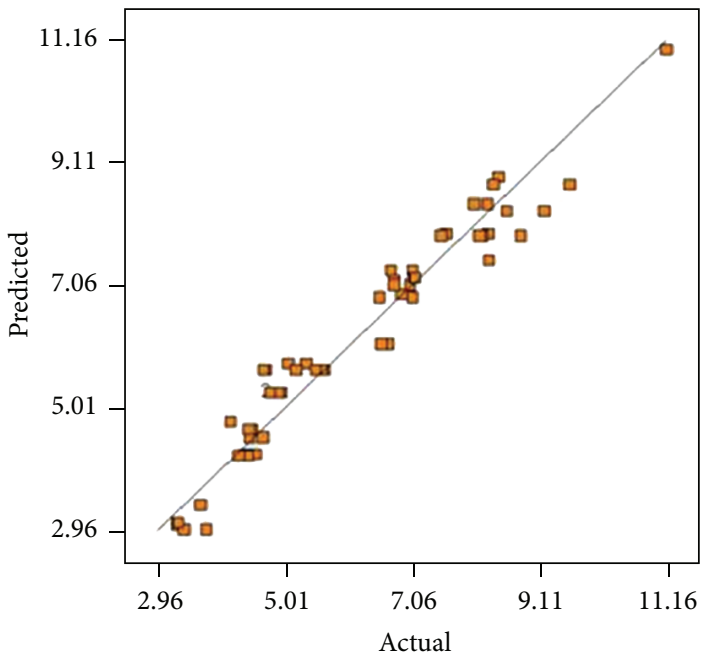

(d)

FIGURE 2: Response surface plot for MRR: (a) interaction plot between pulse off time and peak current, (b) interaction plot between pulse off time and spark gap voltage, (c) normal probability plot residuals, (d) actual versus predicted values.

$B^{2}, C^{2}, E^{2}, F^{2}$, and $A D$ were significant model terms. The lack of fit $F$ value of 0.1719 implies that it is not significant compared to pure error. The "Pred. R-squared" of 0.8191 is in reasonable agreement with the "Adj. $R$-squared" of 0.8706 . This model can be used to navigate the design space. The regression model for overcut is given as

$$
\begin{aligned}
\text { Overcut }= & 102.82449-17.91667 \times \text { Pulse on Time } \\
& -1.55367 \times \text { Pulse off Time }-0.56702 \\
& \times \text { Peak Current }-0.78333 \\
& \times \text { Spark Gap Voltage }+1.83519 \\
& \times \text { Wire Feed }+0.020770 \times \text { Wire Tension } \\
& +0.010355 \times \text { Pulse off Time }{ }^{2} \\
& +0.00165104 \times \text { Peak Current }{ }^{2}-0.12315
\end{aligned}
$$

$\times$ Wire Feed $^{2}-0.0000110288$

$\times$ Wire Tension $^{2}+0.75000$

$\times$ Pulse on Time $\times$ Spark Gap Voltage

$+0.00386905 \times$ Pulse off Time

$\times$ Peak Current.

Figure 3(a) shows the three-dimensional response surface plots for the response overcut in terms of pulse on time and spark gap voltage. It was observed from these plots that the overcut is increased by increasing the pulse on time $0.7 \mu \mathrm{s}$ to $1.1 \mu \mathrm{s}$ and parallel decreasing of spark gap voltage. Due to increase in pulse on time, discharge energy in the spark gap increases. At high level of discharge energy in the spark gap leading to higher overcut [24], the overcut was observed 


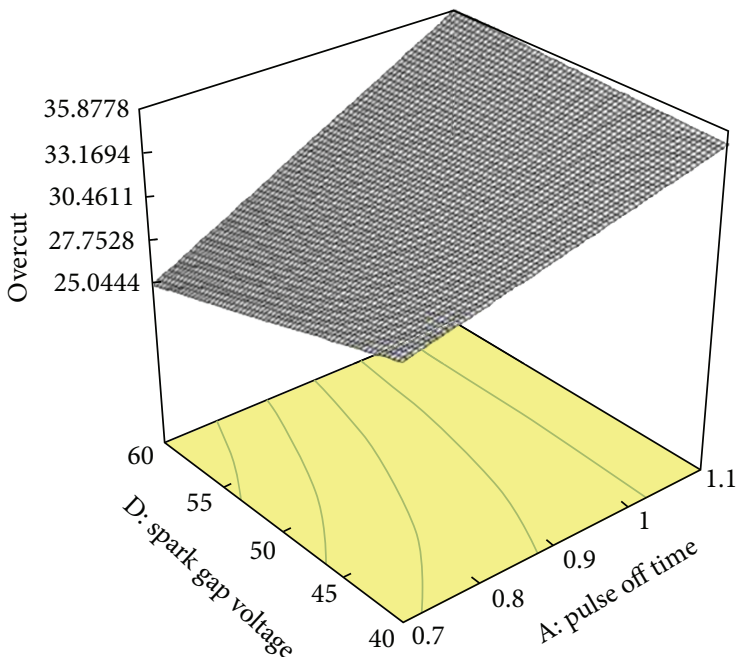

(a)

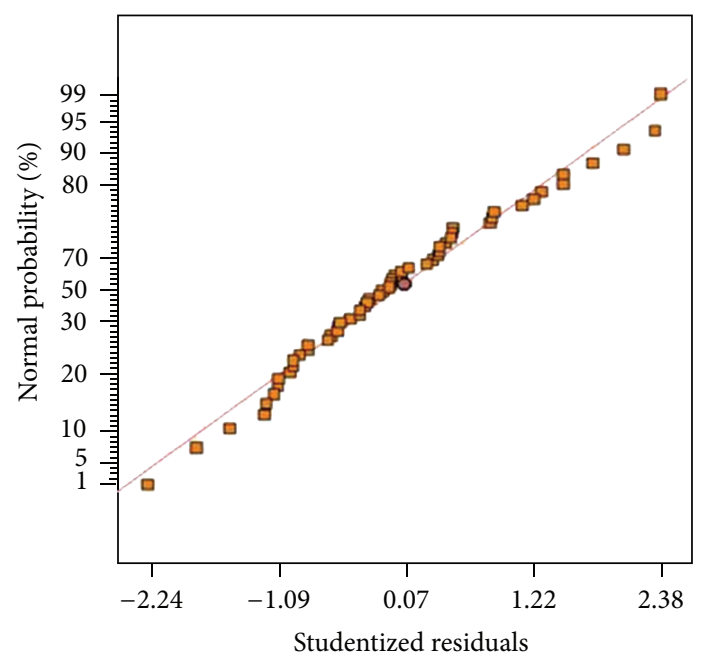

(c)

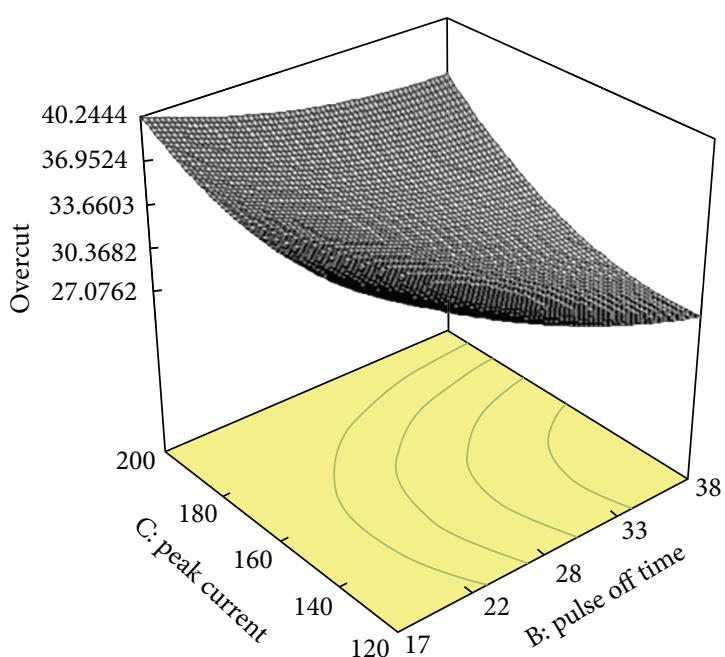

(b)

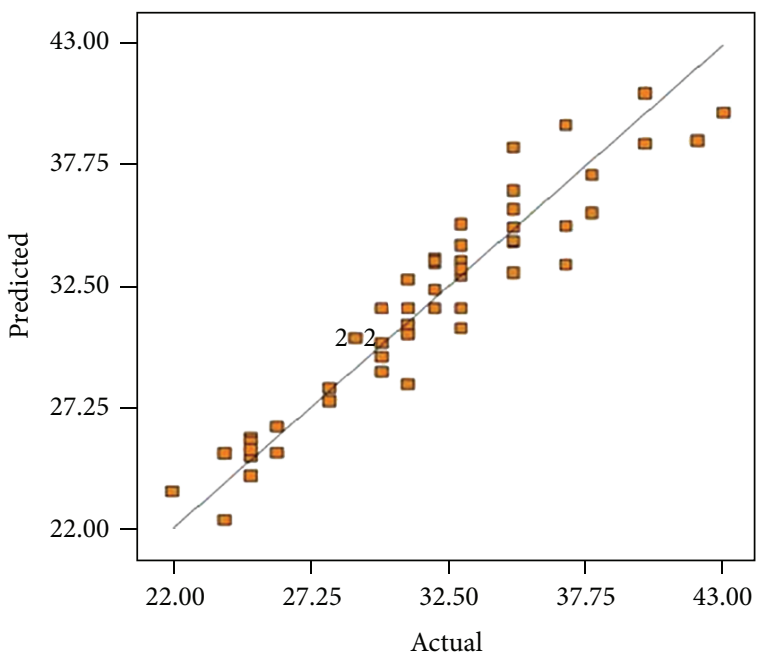

(d)

FIGURE 3: Response surface plot for overcut: (a) interaction plot between pulse on time and spark gap votage, (b) interaction plot between pulse off time and peak current, (c) normal probability plot residuals, (d) actual versus predicted values.

during increasing pulse on time with value of $26.85 \mu \mathrm{m}$ to $34.07 \mu \mathrm{m}$. With further decrease of spark gap voltage $60 \mathrm{~V}$ to $40 \mathrm{~V}$, the overcut also increased. It was found that decreasing the spark gap voltage lowers the spark gap and increases the molten metal in the gap due to its high thermal energy. The overcut was observed during decrease of spark gap voltage with value of $25.07 \mu \mathrm{m}$ to $35.87 \mu \mathrm{m}$. Figure 3(b) shows the three-dimensional response surface and contour plot between pulse off time and peak current. It was observed from these plots that the overcut is decreased by increasing the pulse off time from $17 \mu$ s to $38 \mu$ s simultaneously and decreasing peak current from $200 \mathrm{~A}$ to $120 \mathrm{~A}$. It was found that by decreasing the peak current which leads to lesser discharge energy in the spark so that wire bending and vibration reduced may result in lesser overcut. By increasing the pulse off time and spark gap voltage means increasing the pulse frequency so that lesser amount of debris in the electrical discharges which may result in lesser overcut. In order to obtain the lesser overcut, that is, $22 \mu \mathrm{m}$ of the optimal parametric combination is pulse on time $=0.7 \mu \mathrm{s}$, pulse off time $=28 \mu \mathrm{s}$, peak current $=160 \mathrm{~A}$, spark gap voltage $=60 \mathrm{~V}$, wire feed $=4 \mathrm{~m} / \mathrm{min}$, and wire tension $=950$ grams. Figures 3(c) and 3(d) display the normal probability plot of residuals and residual versus predicted plots for overcut. It is observed that the residuals generally fall on a straight line implying that the errors are normally distributed.

\subsection{Effect of Process Parameters on the Surface Roughness.} Surface roughness was an important process reaction, which dictates the condition of the surface component which has to be machined. If the surface finish of the machined work material was the decisive factor due to its application requirements, then the work material must be machined with low 


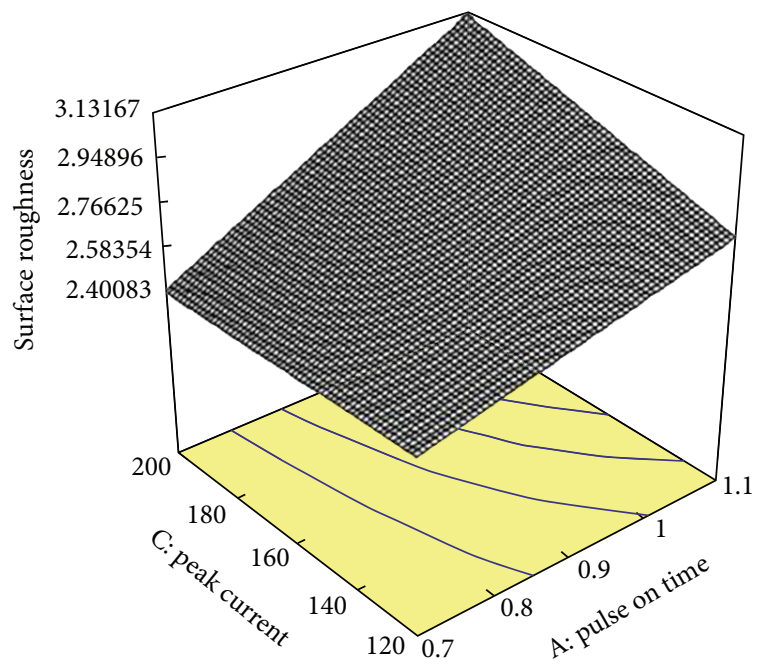

(a)

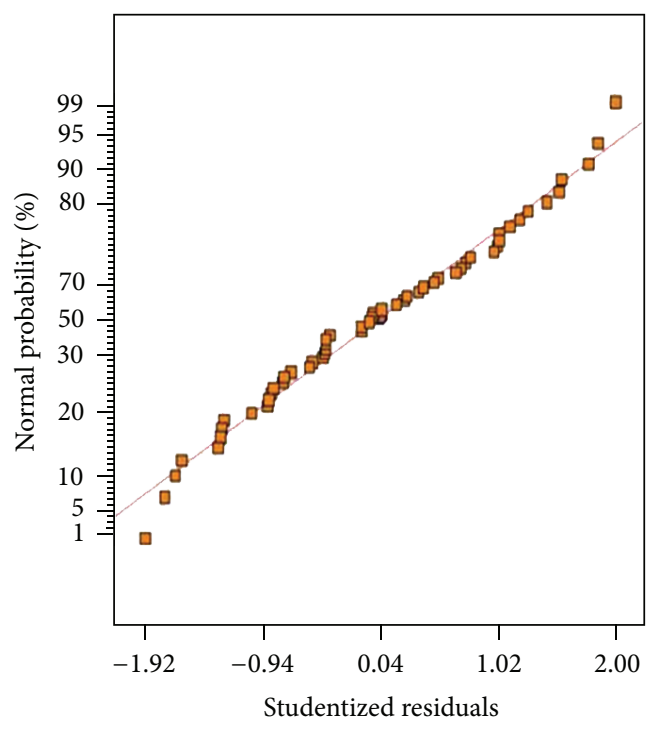

(b)

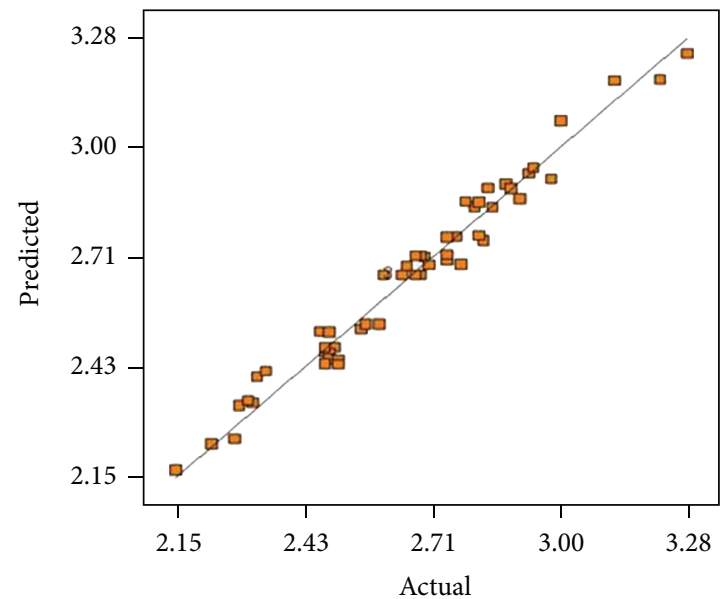

(c)

FIGURE 4: Response surface plot for surface roughness: (a) interaction plot between pulse on time and peak current, (b) normal probability plot residuals, (c) actual versus predicted values.

material removal rate. Equation represents the relationship between machining parameters and surface roughness, which is the result of developed statistical model for surface roughness

Surface Roughness

$$
\begin{aligned}
= & 3.86021-0.76667 \\
& \times \text { Pulse on Time }-0.035278 \\
& \times \text { Pulse off Time }-0.00922396 \\
& \times \text { Peak Current }-0.00866667 \\
& \times \text { Spark gap Voltage }+0.1247 \text { Wire Feed } \\
& -0.000365432 \times \text { Wire Tension } \\
& +0.00031746 \times \text { Pulse off } \text { Time }^{2}
\end{aligned}
$$

$-0.00875 \times$ Wire Feed ${ }^{2}$

$+0.000000191358 \times$ Wire Tension ${ }^{2}$

+ $0.012969 \times$ Pulse on Time $\times$ Peak Current.

Based on ANOVA as shown in Table 5, it implied that pulse on time, pulse off time, peak current, and spark gap voltage were significant to surface roughness. In addition to this normal plots of residuals and residual versus predicted has also been drawn. The data is normally distributed. It was observed from Figures 4(b) and 4(c) that all the experimental results are approximately very close to the predicted values, and hence the developed model can be effectively used to predict the surface roughness in WEDM of pure titanium. The $P$ value for lack of fit is 0.1173 suggesting that this model adequately fits the data. The "Pred $R$-Squared" of 0.9527 is 
TABLE 4: The analysis of variance for main and interaction effects of parameters on overcut.

\begin{tabular}{|c|c|c|c|c|c|c|c|}
\hline Source & SS & DOF & MS & $F$-value & Prob. $>F$ & At $95 \% \mathrm{CI}$ & $\%$ Contribution \\
\hline Model & 1101.81 & 12 & 91.82 & 30.71 & $<0.0001$ & significant & \\
\hline Pulse on time & 368.17 & 1 & 368.17 & 123.16 & $<0.0001$ & significant & 30.07 \\
\hline Pulse off time & 352.67 & 1 & 352.17 & 117.97 & $<0.0001$ & significant & 28.76 \\
\hline Peak current & 176.04 & 1 & 176.04 & 58.89 & $<0.0001$ & significant & 14.37 \\
\hline Spark gap voltage & 28.17 & 1 & 28.17 & 9.42 & $<0.0038$ & significant & 2.30 \\
\hline Pulse off time ${ }^{2}$ & 14.22 & 1 & 14.22 & 4.76 & 0.0350 & significant & 1.16 \\
\hline Peak current ${ }^{2}$ & 76.13 & 1 & 76.13 & 25.47 & $<0.0001$ & significant & 6.21 \\
\hline Wire feed ${ }^{2}$ & 13.40 & 1 & 13.40 & 4.48 & 0.0403 & significant & 1.09 \\
\hline Wire tension ${ }^{2}$ & 54.41 & 1 & 54.41 & 18.20 & $<0.0001$ & significant & 4.44 \\
\hline Pulse on time $\times$ spark gap voltage & 36.00 & 1 & 36.00 & 12.04 & 0.0012 & significant & 2.94 \\
\hline Pulse off time $\times$ peak current & 21.13 & 1 & 21.13 & 7.07 & 0.0111 & significant & 1.72 \\
\hline Lack of fit & 115.73 & 36 & 3.21 & & 0.1719 & not significant & \\
\hline \multicolumn{8}{|l|}{$R^{2}=0.8999$} \\
\hline \multicolumn{8}{|l|}{$R^{2}$ adjusted $=0.8706$} \\
\hline Predicted $R^{2}=0.8191$ & & & & & & & \\
\hline
\end{tabular}

SS: sum of square, DOF: degree of freedom, MS: mean square, F-value: Fisher value.

TABLE 5: The analysis of variance for main and interaction effects of parameters on surface roughness.

\begin{tabular}{|c|c|c|c|c|c|c|c|}
\hline Source & SS & DOF & MS & $F$-Value & $P>F$ & At $95 \% \mathrm{CI}$ & \% Contribution \\
\hline Model & 3.08 & 10 & 0.31 & 145.26 & $<0.0001$ & Significant & \\
\hline Pulse on time & 1.64 & 1 & 1.64 & 775.10 & $<0.0001$ & Significant & 55.0 \\
\hline Pulse off time & 0.84 & 1 & 0.84 & 396.22 & $<0.0001$ & Significant & 28.0 \\
\hline Peak current & 0.23 & 1 & 0.23 & 108.54 & $<0.0001$ & Significant & 8.0 \\
\hline Spark gap voltage & 0.18 & 1 & 0.18 & 85.03 & $<0.0001$ & Significant & 6.0 \\
\hline Pulse off time ${ }^{2}$ & 0.013 & 1 & 0.013 & 6.36 & 0.0155 & Significant & 0.41 \\
\hline Wire feed ${ }^{2}$ & 0.068 & 1 & 0.068 & 32.18 & $<0.0001$ & Significant & 2.15 \\
\hline Wire tension ${ }^{2}$ & 0.019 & 1 & 0.019 & 8.90 & 0.0047 & Significant & 0.6 \\
\hline Pulse on time $\times$ peak current & 0.086 & 1 & 0.086 & 40.62 & $<0.0001$ & Significant & 2.71 \\
\hline Lack of fit & 0.087 & 38 & 0.002295 & 2.91 & 0.1173 & Not significant & \\
\hline \multicolumn{8}{|l|}{$R^{2}=0.9712$} \\
\hline \multicolumn{8}{|l|}{$R^{2}$ adjusted $=0.9646$} \\
\hline Predicted $R^{2}=0.9527$ & & & & & & & \\
\hline
\end{tabular}

SS: sum of square, DOF: degree of freedom, MS: mean square, $F$-value: Fisher value.

in reasonable agreement with the "Adj $R$-Squared" of 0.9646. It was observed from Figure 4(a) that the surface roughness is affected by interaction between pulse on time and peak current with value of 2.41 to $2.72 \mu \mathrm{m}$. When pulse on time was increased from 0.7 to $1.1 \mu \mathrm{s}$ with peak current of $200 \mathrm{~A}$, the results surface roughness was increased from 2.40 to $3.13 \mu \mathrm{m}$. High pulsed current caused frequent cracking of dielectric fluid, causing more melt expulsions and larger tensile stresses. These effects were turned in poor surface finish. At higher pulse on time and peak current, the discharge energy per pulse increases which produces the deeper and wider overlapping craters, pockmarks, globules of debris, and microcracks on the machined samples as seen in SEM micrographs (Figures 5 and 6). The rapid cooling and heating effects generate gas bubbles that explode when the discharge ceases. It is clear from Figure 5(b) that the diameter and depth of crater were deeper and wider due to that high peak current $(200 \mathrm{~A})$ and low pulse off time $(17 \mu \mathrm{s})$ may result in increasing the surface roughness $(2.98 \mu \mathrm{m})$. At higher peak current, the impact of discharge energy on the surface of workpiece becomes greater, and thus resulting erosion leads to the increase in deterioration of surface roughness [25]. It was observed from Figure 6(b) that some titanium particles were protruding and completely dislodged from the surface which may happen at higher pulse on time $(1.1 \mu \mathrm{s})$ and peak current (200 A). The minimum surface roughness is obtained with value of $2.15 \mu \mathrm{m}$ in experiment no. 15 .

\section{Crack Formation}

Based on the previous research work done by Lee and Li [22], crack formation was usually associated with the development of high thermal stresses which exceed the fracture strength, 


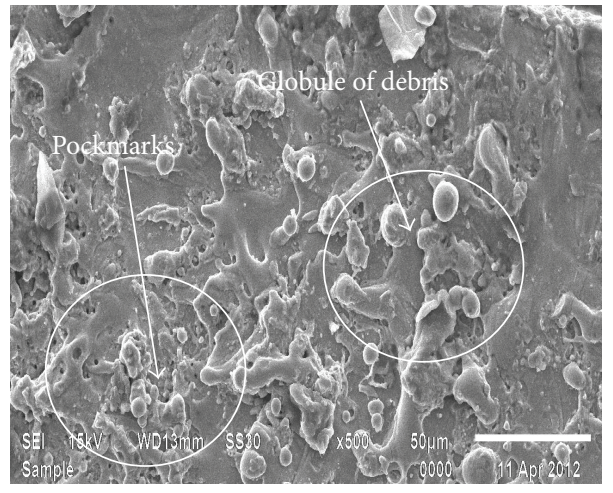

(a)

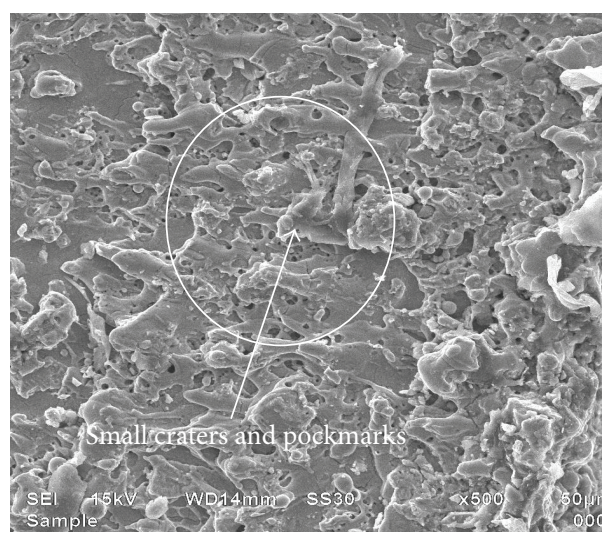

(c)

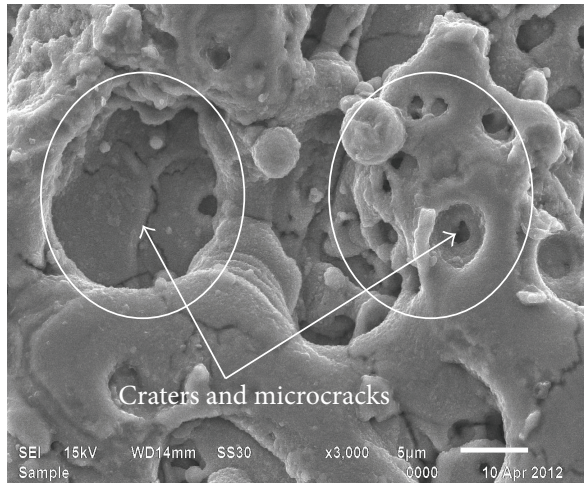

(b)

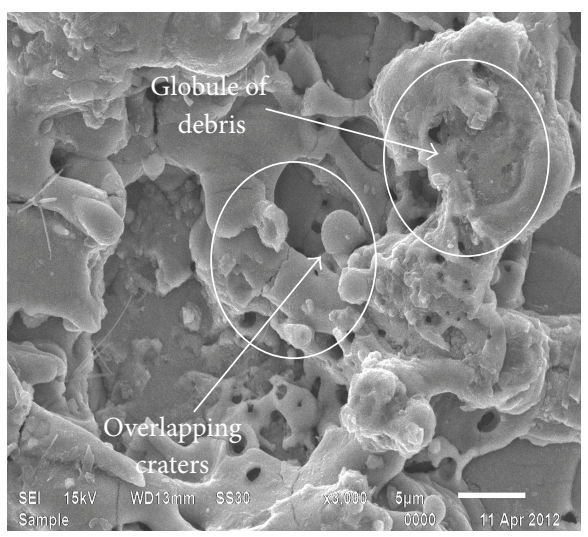

(d)

FIGURE 5: SEM micrograph (1000x, 2000x, 3000x, and 500x): (a) experiment no. 1 , at $T_{\text {on }}=1.1 \mu \mathrm{s}, T_{\text {off }}=28 \mu \mathrm{s}, \mathrm{Ip}=200 \mathrm{~A}, \mathrm{SV}=50 \mathrm{~V}, \mathrm{WF}=$ $7 \mathrm{~m} / \mathrm{min}, \mathrm{WT}=500$ grams; (b) experiment no. 35, at $T_{\text {on }}=1.1 \mu \mathrm{s}, T_{\text {off }}=17 \mu \mathrm{s}, \mathrm{Ip}=160 \mathrm{~A}, \mathrm{SV}=40 \mathrm{~V}, \mathrm{WF}=7 \mathrm{~m} / \mathrm{min}, \mathrm{WT}=950 \mathrm{grams}$; (c) experiment no. 15, at $T_{\text {on }}=0.7 \mu \mathrm{s}, T_{\text {off }}=28 \mu \mathrm{s}, \mathrm{Ip}=120 \mathrm{~A}, \mathrm{SV}=50 \mathrm{~V}, \mathrm{WF}=7 \mathrm{~m} / \mathrm{min}, \mathrm{WT}=500$ grams; (d) experiment no. 6, at $T_{\text {on }}=1.1 \mu \mathrm{s}$, $T_{\text {off }}=28 \mu \mathrm{s}, \mathrm{Ip}=160 \mathrm{~A}, \mathrm{SV}=40 \mathrm{~V}, \mathrm{WF}=4 \mathrm{~m} / \mathrm{min}, \mathrm{WT}=950$ grams.

as well as with plastic deformation. In addition, the formation of microcracks not only was influenced by the setting of machining parameters but also depended on several materials properties such as tensile strength, thermal conductivity, thermal expansion coefficient, and Young modulus. In order to examine the subsurface cracks of machined samples by WEDM indicate that the material is amorphous either in free form and/or in compound form. The formation of microcracks is generally accompanied by rapid cooling and heating by dielectric fluid. The heating and cooling process was increasing the yield stress and the material plastically deformed during heating that build up the tensile stresses which leads to crack formation. The crack distribution on the surface was observed with evaluating the crack density and mean free path of the cracks $[27,28]$. The surface crack densities at various peak current and pulse on time was observed in Figures 7(a)-7(d). It was observed that the cracks were developed due to high pulse on time and peak current. Due to increase of pulse on time and peak current leads to intense heat conditions on the work piece causing surface cracks developed on the material. The surface cracks density was observed wider due to free path of debris and also penetrates more deeply into original material. Overall, the results show that the surface cracks were developed by increasing pulse on time and peak current.Cracks formed in crater continue to propagate when another discharge takes place in the neighborhood as shown in Figure 7(c). It can be noted that the intersection or inter-granular points of crack paths usually form perpendicular angles as shown in Figure $7(b)$. The penetrating cracks penetrate the entire subsurface to an extent into the parent material and are usually observed when machining is performed in deionized water as shown in Figure 7(a). Penetrating cracks tend to form a closed loop around the crater rim. These penetrating cracks at the subsurface mainly due to high stress concentrations are induced at crater rims during solidification.

\section{Effect of Process Parameters on Recast Layer (RL)}

The recast layer was observed at the cross-section of the WEDM surface. The recast layer is defined as the material melted by electrical discharge and resolidified on the work surface without being ejected nor removed by dielectric fluid [29]. It is very difficult to remove, and its appearance is 


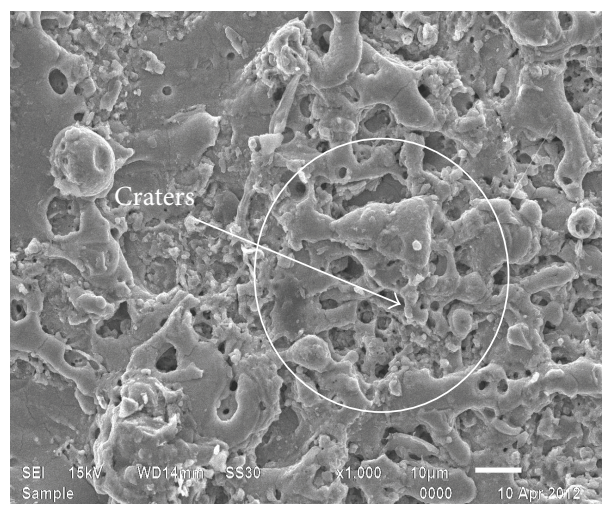

(a)

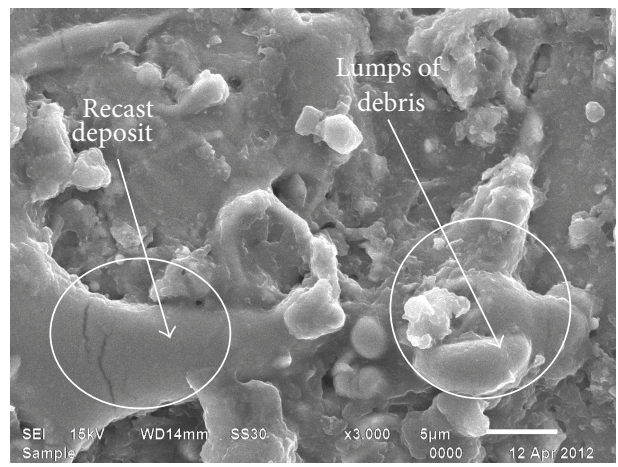

(c)

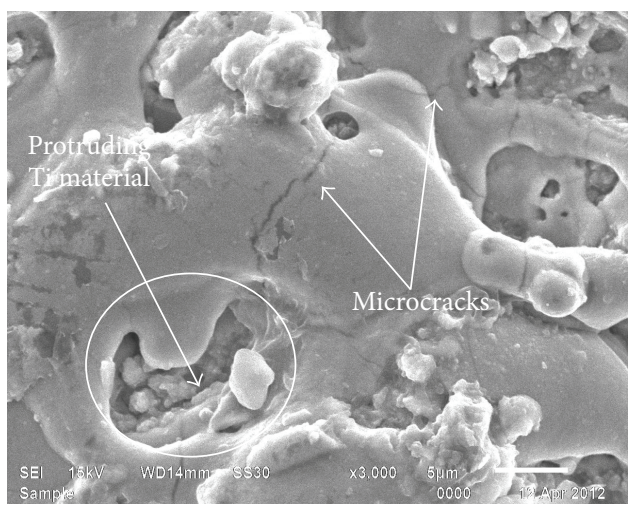

(b)

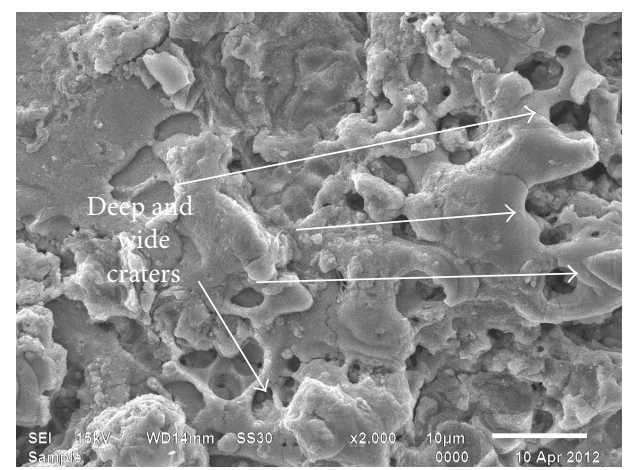

(d)

Figure 6: SEM micrograph (1000x, 2000x, 3000x, and 500x): (a) experiment no. 1 , at $T_{\text {on }}=1.1 \mu \mathrm{s}, T_{\text {off }}=28 \mu \mathrm{s}, \mathrm{Ip}=200 \mathrm{~A}, \mathrm{SV}=50 \mathrm{~V}, \mathrm{WF}=$ $7 \mathrm{~m} / \mathrm{min}, \mathrm{WT}=500$ grams; (b) experiment no. 52 , at $T_{\text {on }}=1.1 \mu \mathrm{s}, T_{\text {off }}=28 \mu \mathrm{s}, \mathrm{Ip}=200 \mathrm{~A}, \mathrm{SV}=50 \mathrm{~V}, \mathrm{WF}=7 \mathrm{~m} / \mathrm{min}, \mathrm{WT}=1400 \mathrm{grams} ;(\mathrm{c})$ experiment no. 50, at $T_{\text {on }}=1.1 \mu \mathrm{s}, T_{\text {off }}=17 \mu \mathrm{s}, \mathrm{Ip}=160 \mathrm{~A}, \mathrm{SV}=60 \mathrm{~V}, \mathrm{WF}=7 \mathrm{~m} / \mathrm{min}, \mathrm{WT}=950$ grams; (d) experiment no. 36 , at $T_{\text {on }}=0.9 \mu \mathrm{s}$, $T_{\text {off }}=17 \mu \mathrm{s}, \mathrm{Ip}=200 \mathrm{~A}, \mathrm{SV}=50 \mathrm{~V}, \mathrm{WF}=10 \mathrm{~m} / \mathrm{min}, \mathrm{WT}=950$ grams.

observed through a scanning electron microscope at different levels of magnification. Below the recast layer there is the heat-affected zone. The recast layer thickness was changed due to superficial hardening of the work material by the discharge heat of electrical spark. The intensity of spark depends on peak current, pulse on time, and pulse off time. The thickness of recast layer of WEDM surface was increased due to increase of peak current and pulse on time and decrease of pulse off time as observed in Figures $8(a)-8(d)$. Due to increase of pulse on time and peak current, the melting of isothermals becomes more intense, which further penetrates into base metal, and the result extends the thickness of recast layer. It is clear that recast layers appear as nonuniform and have wave-like pattern. The average thickness of recast layer, as observed, is having a variation of $6 \mu \mathrm{m}$ to $18 \mu \mathrm{m}$.

\section{Analyzing the Wire Wear Rate and Wire Rupture}

In WEDM, the cutting is done by brass wire having tensile strength of $900 \mathrm{~N} / \mathrm{mm}^{2}$. The occurrence of wire rupture would result in decrease of machining accuracy and the deterioration of quality of machined surface. Due to the thermal effects that develop at the interface zone between the tool and work piece, a lot of material changes take place on the surface of tool and work piece [30]. In this regard, the material transfer characteristic of machined wire was investigated. The wire is fed through guide rolls causes abrasive action between wire and work piece may result in reduced the cross-section and also the surface characteristics of the work piece gets affected. Hence proper care should be taken in loading the spool to the machine to avoid wire deflection and breakage. In this study there are two types of wire rupture that was observed; one is due to high peak current and the other is increasing spark frequency. Figures 9(b)-9(e) show the micrograph of wear out wire. There are many different craters and residuals of debris adhered to the surface of wire electrode. The residuals of copper, carbon, oxygen, and titanium were detected in wire electrode which was observed by EDX shown in Figure 9(f). This may be due to the melting and resolidification of the titanium and brass wire electrode after WEDM. By increasing the peak current leads to generation of higher discharge energy in the spark gap may result increase the wire wear rate and wire breakage. When the debris in the gap cannot be flushed properly by dielectric may result the arcing was produced and wire breakage occurs. In addition, since the spark gap is too narrow, a portion of discharging energy was absorbed by wire electrode. Hence the surface of wire melts due to the induced high temperature. 


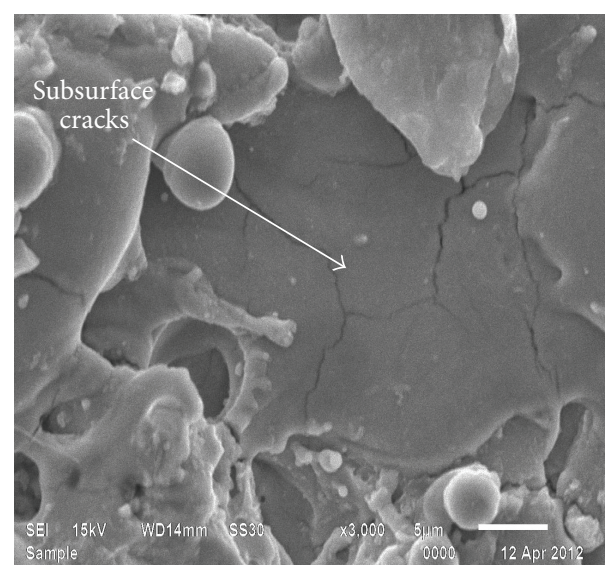

(a)

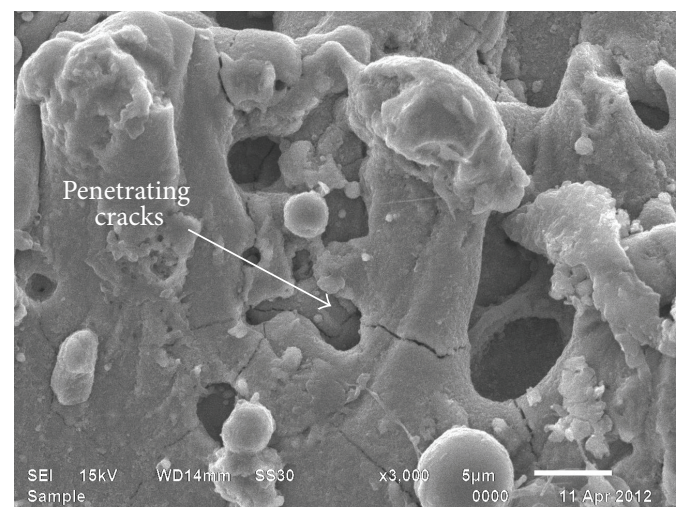

(c)

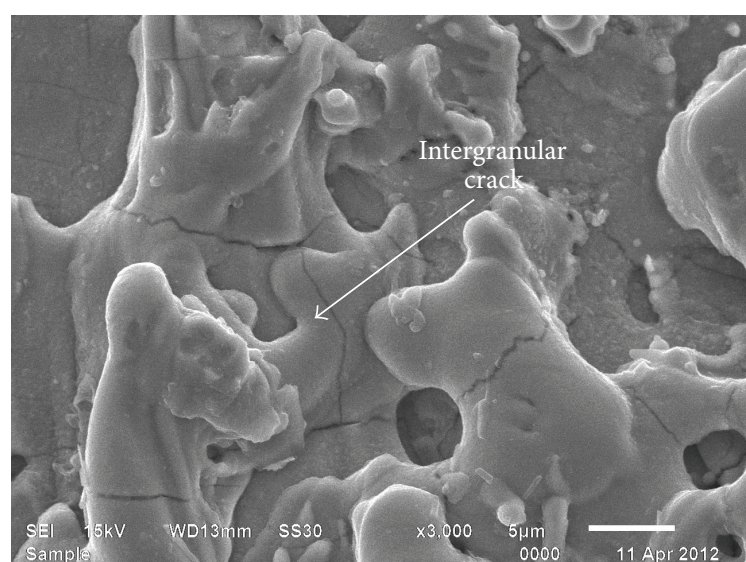

(b)

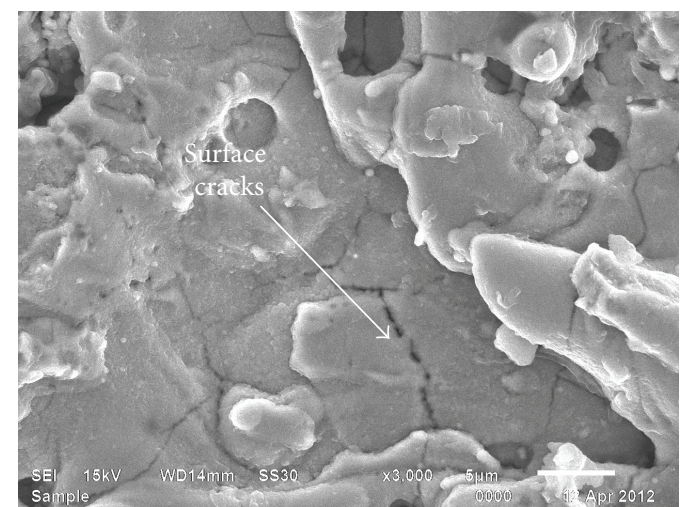

(d)

FiguRE 7: SEM micrographs of subsurface cracks at various pulse on time and peak current: (a) $T_{\text {on }}=1.1 \mu \mathrm{s}, \mathrm{Ip}=160 \mathrm{~A},(\mathrm{~b}) T_{\text {on }}=1.1 \mu \mathrm{s}, \mathrm{Ip}=$ $200 \mathrm{~A}$, (c) $T_{\text {on }}=0.9 \mu \mathrm{s}, \mathrm{Ip}=120 \mathrm{~A}$, (d) $T_{\text {on }}=0.9 \mu \mathrm{s}, \mathrm{Ip}=160 \mathrm{~A}$.

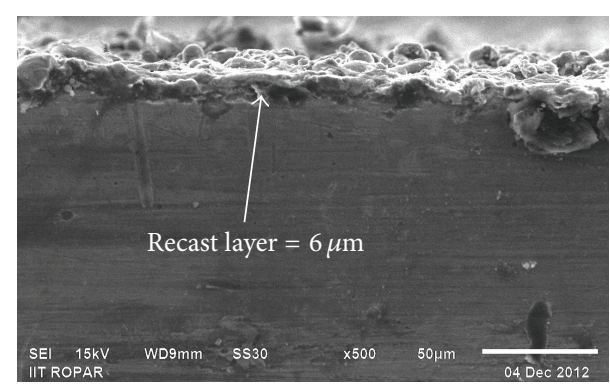

(a)

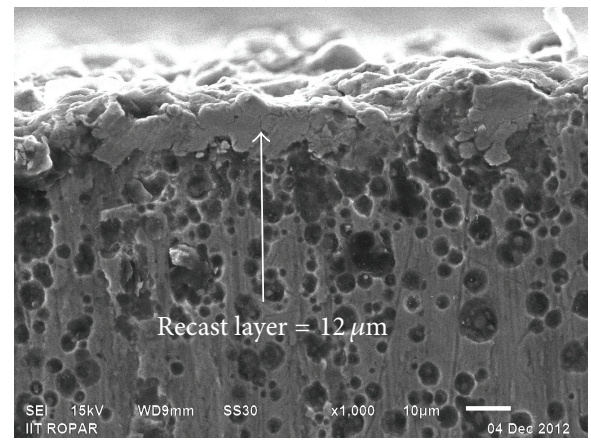

(c)

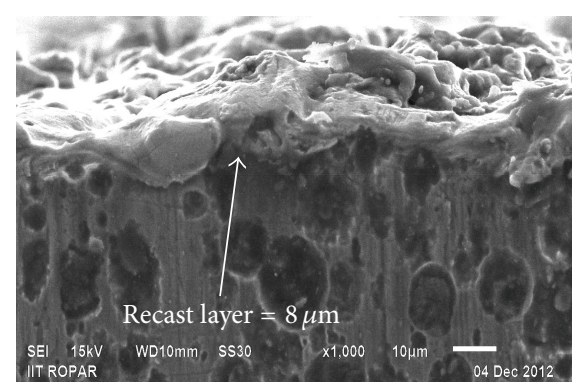

(b)

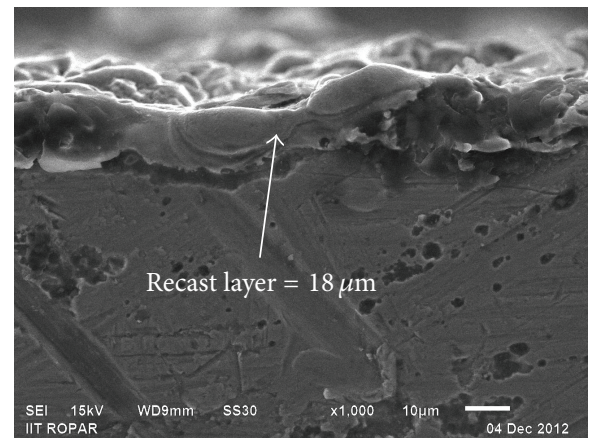

(d)

FIGURE 8: SEM micrographs of recast layer at various pulse on time and peak current: (a) $T_{\text {on }}=1.1 \mu \mathrm{s}, \mathrm{Ip}=160 \mathrm{~A}$, (b) $T_{\text {on }}=1.1 \mu \mathrm{s}$, Ip $=200 \mathrm{~A}$, (c) $T_{\text {on }}=0.9 \mu \mathrm{s}, \mathrm{Ip}=120 \mathrm{~A}$, (d) $T_{\text {on }}=0.9 \mu \mathrm{s}$, Ip $=160 \mathrm{~A}$. 


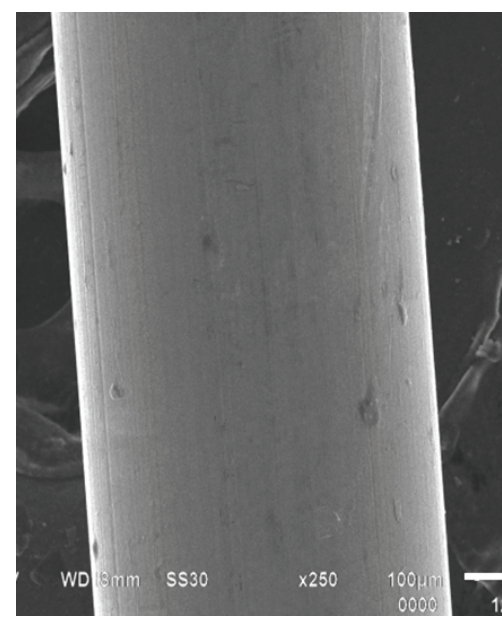

(a)

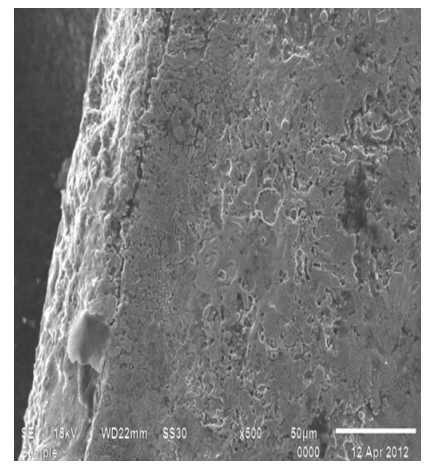

(d)

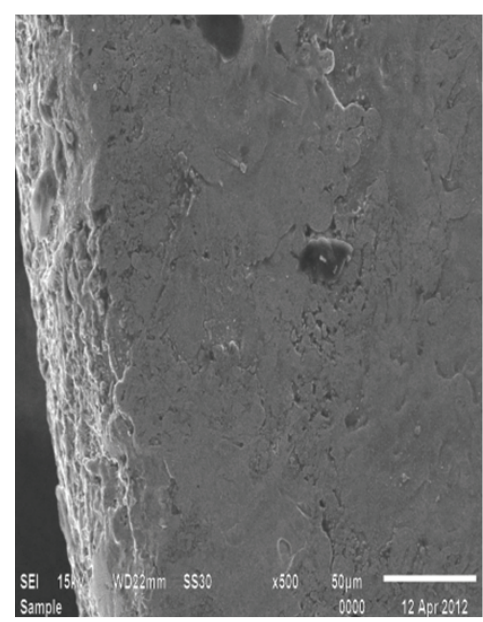

(b)

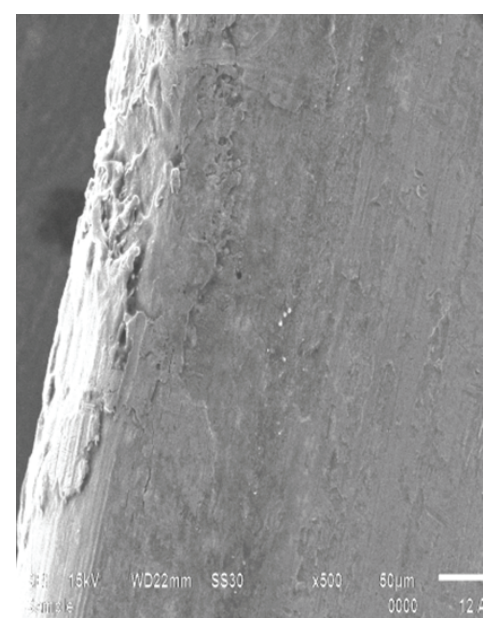

(c)

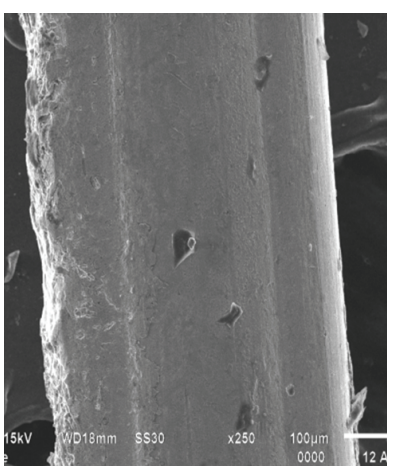

(e)

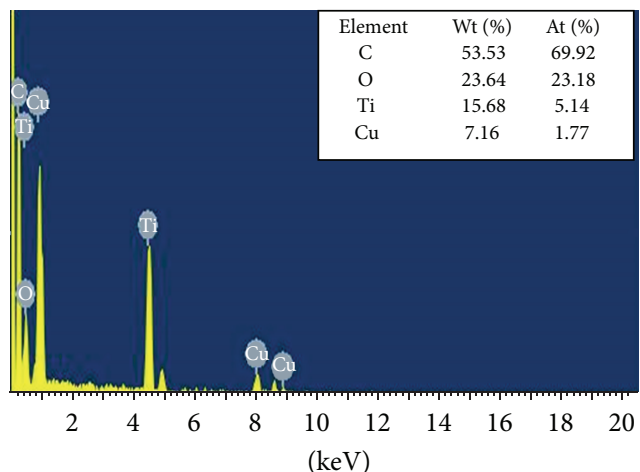

(f)

FIGURE 9: SEM micrographs (250x and 500x) of the machined wire electrode surface for machining of pure titanium at (a) fresh wire; (b) experiment no. 1 , at $T_{\text {on }}=1.1 \mu \mathrm{s}, T_{\text {off }}=28 \mu \mathrm{s}, \mathrm{Ip}=200 \mathrm{~A}, \mathrm{SV}=50 \mathrm{~V}, \mathrm{WF}=7 \mathrm{~m} / \mathrm{min}, \mathrm{WT}=500$ grams; (c) experiment no. 35 , at $T_{\text {on }}=1.1 \mu \mathrm{s}$, $T_{\text {off }}=17 \mu \mathrm{s}, \mathrm{Ip}=160 \mathrm{~A}, \mathrm{SV}=40 \mathrm{~V}, \mathrm{WF}=7 \mathrm{~m} / \mathrm{min}, \mathrm{WT}=950$ grams; ((d),(e)) experiment no. 15 , at $T_{\text {on }}=0.7 \mu \mathrm{s}, T_{\text {off }}=28 \mu \mathrm{s}, \mathrm{Ip}=120 \mathrm{~A}, \mathrm{SV}=$ $50 \mathrm{~V}, \mathrm{WF}=7 \mathrm{~m} / \mathrm{min}, \mathrm{WT}=500$ grams; (f) $\mathrm{EDX}$ of machined wire electrode at $T_{\text {on }}=0.9 \mu \mathrm{s}, T_{\text {off }}=38 \mu \mathrm{s}, \mathrm{Ip}=160 \mathrm{~A}, \mathrm{SV}=50 \mathrm{~V}, \mathrm{WF}=4 \mathrm{~m} / \mathrm{min}$, $\mathrm{WT}=500$ grams.

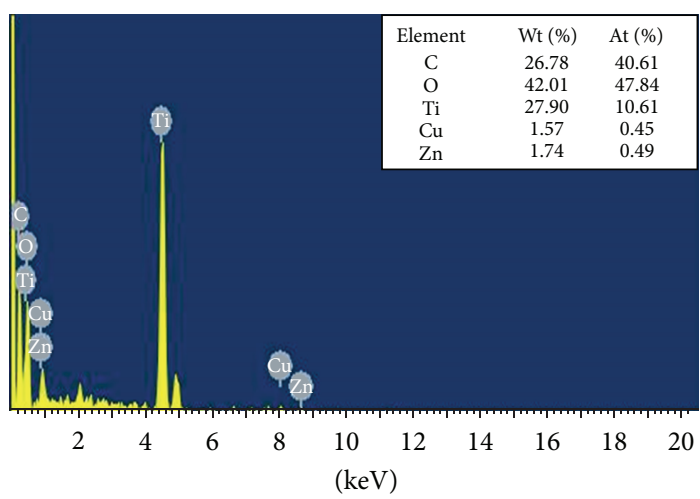

(a)

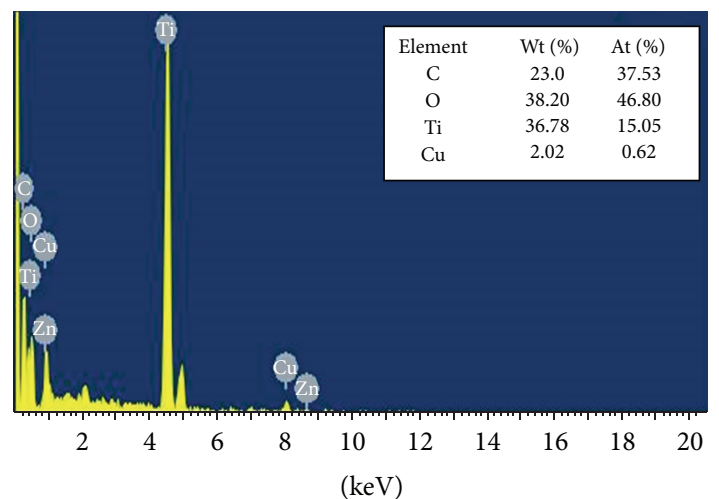

(b)

FIGURE 10: EDX analysis of pure titanium after WEDM. 


\section{EDX and XRD Analysis}

The compositions of WEDM samples were detected through EDX. Figure 10 shows the energy dispersive X-ray (EDX) of affected surfaces, which are obtained by accelerating voltage of $3 \mathrm{kv}$. Through EDX technique, the residuals of copper and Zinc were also detected in the machined samples. This may be due to the melting, evaporation, and resolidification of the brass wire electrode and may result they were transferred to the work material. The presence of oxygen in the titanium probably was due to oxidation as a result of high temperature involved in the process. Although EDX result showed that carbon and oxygen also existed in the titanium, these elements were observed due to the fact that dielectric fluid with debris normally contains carbon and oxygen. Further, the XRD pattern analysis confirms the migration of tool elements (anode), and dielectric fluid elements were migrated to the work surface, and they formed different compounds like titanium dioxide (rutile) $\left(\mathrm{TiO}_{2}\right),\left(\mathrm{TiO}_{0.325}\right), \mathrm{Ti}_{2} \mathrm{O}_{3}$, Ilmenite $\left(\mathrm{Fe}_{2} \mathrm{Ti}_{4} \mathrm{O}\right)$, and copper titanium dioxide $\left(\mathrm{Cu}_{3} \mathrm{TiO}_{4}\right)$. The phases were identified in the form of peaks at $2 \theta$ scale. The plots of identified phases were shown in Table 6 and Figure 11.

\section{Multiresponse Optimization Based on Desirability}

Optimum selection of process parameters combinations is needed for obtaining higher MRR as well as minimum overcut and surface roughness. This is obtained by applying the multiresponse optimization through desirability function. The desirability approach is one of the useful approaches to optimize the multiple responses. This approach includes the concept of desirability functions. The general approach is to first convert each response $\left(y_{i}\right)$ into an individual desirability function $\left(d_{i}\right)$ and varied over the range $\leq d_{i} \leq 1$. Where if the response $y_{i}$ is at its goal or target, then $d_{i}=1$. The response is outside an acceptable region $\left(d_{i}=0\right)$. The weight of the desirability function for each response defines its shape. For each response, weights are assigned $\left(r_{i}\right)$ to emphasize or de-emphasize the target. Finally, the individual desirability functions are combined to provide a measure of the overall desirability of the multiresponse system. This measure of composite desirability is the weighted geometric mean of the individual desirability for the responses. The optimal operating conditions are determined by maximizing the composite desirability [31]. Composite desirability is the weighted geometric mean of the individual desirabilities for the responses. The factor settings with maximum total desirability are considered to be the optimal parameter conditions. The simultaneous objective function is a geometric mean of all transformed responses. The optimization is accomplished by the following:

(i) obtaining the individual desirability (d) for each response;

(ii) combining the individual desirabilities to obtain the combined or composite desirability $(D)$;

(iii) maximizing the composite desirability and identifying the optimal input variable settings.
If it is desirable to maximize a response, the individual desirability is calculated as

$$
d_{i}= \begin{cases}0, & y_{i}<L_{i}, \\ \left(\frac{y_{i}-L_{i}}{T_{i}-L_{i}}\right)^{w}, & L_{i} \leq y_{i} \leq T_{i}, \\ 1, & y_{i}>T_{i} .\end{cases}
$$

If the target $\left(T_{i}\right)$ is to minimize a response, the individual desirability is calculated as

$$
d_{i}= \begin{cases}1, & y_{i}<T_{i}, \\ \left(\frac{U_{i}-y_{i}}{U_{i}-T_{i}}\right)^{w}, & T_{i} \leq y_{i} \leq U_{i}, \\ 0, & y_{i}>U_{i},\end{cases}
$$

where $L_{i}=$ lower limit value of response $y_{i}$ and

$$
U_{i}=\text { upper limit value of response } y_{i} .
$$

If the object for the response is a target value, then individual desirability is calculated as

$$
\begin{gathered}
d_{i}=\left[\frac{\left(y_{i}-L_{i}\right)}{\left(T_{i}-L_{i}\right)}\right]^{w}, \quad L_{i} \leq y_{i} \leq T_{i}, \\
d_{i}=\left[\frac{\left(U_{i}-y_{i}\right)}{\left(U_{i}-T_{i}\right)}\right]^{w}, \quad T_{i} \leq y_{i} \leq U_{i}, \\
d_{i}=0, \quad \text { if } y_{i}<L_{i}, \\
d_{i}=0, \quad \text { if } y_{i}>U_{i} .
\end{gathered}
$$

The factor settings with maximum total desirability are considered to be the optimal parameter conditions. The simultaneous objective function is a geometric mean of all transformed responses:

$$
D=\left(d_{1} \times d_{2} \times d_{3} \times \cdots \times d_{n}\right)^{1 / n}=\left(\prod_{i=1}^{n} d_{i}\right)^{1 / n},
$$

where $n$ is the number of responses in the measure. If any of the responses or factors falls outside the desirability range, the overall function becomes zero. It can be extended to reflect the possible difference in the importance of different responses, where the weight $w_{i}$ satisfies $0<w_{i}<1$ and

$$
\begin{gathered}
w_{1}+w_{2}+\cdots+w_{n}=1, \\
D=\left(d_{1}^{w_{1}} \times d_{2}^{w_{2}} \times \cdots d_{n}^{w_{n}}\right)^{1 / n} .
\end{gathered}
$$

Desirability is an objective function that ranges from zero outside of the limits to one at the goal. The numerical optimization finds a point that maximizes the desirability 
TABLE 6: XRD plot of identified phases.

\begin{tabular}{lcccc}
\hline Ref. code & Compound name & Crystal system & Displacement [ $\left.{ }^{\circ} 2 \mathrm{Th}.\right]^{2}$ & Chemical formula \\
\hline $01-073-1581$ & Titanium oxide & Hexagonal(225) & 0.160 & $\mathrm{TiO}_{0.325}$ \\
$01-083-1284$ & Copper titanium oxide & Rhombohedra(167) & -0.391 & $\mathrm{Cu}_{3} \mathrm{TiO}_{4}$ \\
$00-010-0063$ & Titanium oxide & Cubic(227) & -0.270 & $\mathrm{Ti}_{2} \mathrm{O}_{3}$ \\
$01-075-0402$ & Ilmenite & Rhombohedral (148) & -0.668 & $\mathrm{Fe}_{2} \mathrm{Ti}_{4} \mathrm{O}$ \\
$01-085-0547$ & Zinc titanium oxide & Hexagonal(194) & 0.000 & $\mathrm{ZnTiO}_{3}$ \\
\hline
\end{tabular}

TABLE 7: Constraints of input parameters and responses.

\begin{tabular}{|c|c|c|c|c|c|c|}
\hline Parameters & Target & Lower limit & Upper limit & Lower weight & Upper weight & Importance \\
\hline Pulse on time & & 0.7 & 1.1 & 1 & 1 & 3 \\
\hline Pulse off time & & 17 & 38 & 1 & 1 & 3 \\
\hline Peak current & & 120 & 200 & 1 & 1 & 3 \\
\hline Spark gap voltage & & 40 & 60 & 1 & 1 & 3 \\
\hline Wire feed & & 4 & 10 & 1 & 1 & 3 \\
\hline Wire tension & & 500 & 1400 & 1 & 1 & 3 \\
\hline $\operatorname{MRR}\left(\mathrm{mm}^{3} / \mathrm{min}\right)$ & Maximize & 3.28 & 11.16 & 1 & 1 & 3 \\
\hline Overcut $(\mu \mathrm{m})$ & Minimum & 22 & 43 & 1 & 1 & 3 \\
\hline Surface roughness $(\mu \mathrm{m})$ & Minimum & 2.15 & 3.28 & 1 & 1 & 3 \\
\hline
\end{tabular}

function. The characteristics of a goal may be altered by adjusting the weight or importance. For several responses and factors, all goals get combined into one desirability function. For simultaneous optimization each response must have a low and high value assigned to each goal. The "Goal" field for responses must be one of five choices: "none," "maximum," "minimum," "target," or "in range." In the present investigation, the response parameters MRR, overcut, and surface roughness are chosen to maximize the overall desirability. The $d_{i}$ for "in range" is included in the product of the desirability function " $D$ " but is not counted in determining " $n$ ": $D=\left(\prod d_{i}\right)^{1 / n}$. Table 7 shows the constraints of input parameters and of responses and the goal and weights assigned to each parameter. Table 8 shows the values of 25 levels combinations of process parameters that will give high value of composite desirability (ranged from 0.603 to 0.527 ), and the values of predicted responses obtained are also given. The values of composite desirability for 54 performed experimental runs are also shown in Table 8. The value of composite desirability $(D)$ was taken as 0.603 . Table 9 gives the optimal input process parametric setting for multiresponse optimization. The current optimal process parameter settings are pulse on time of $1.1 \mu \mathrm{s}$, pulse off time of $38 \mu \mathrm{s}$, peak current of $128 \mathrm{~A}$, spark gap voltage of $50 \mathrm{~V}$, wire feed of $4 \mathrm{~m} / \mathrm{min}$, and wire tension of 1350 grams. To show the sensitivity of the results, contour plots for overall desirability and optimized histograms of the three responses MRR, overcut, and surface roughness are shown in Figures 12(a) and 12(b). The nearoptimal region was located close to the right hand center region of the plot, which had a composite desirability value greater than 0.603 that gradually reduced as we moved left and upwards.

\section{Confirmation Experiment}

The confirmatory experiments were performed to verify the optimal input parametric setting for MRR, overcut, and surface roughness and were compared with optimal response values. The observed MRR, overcut, and surface roughness of the experimental results are $8.20 \mathrm{~mm}^{3} / \mathrm{min}, 31.17 \mu \mathrm{m}$, and $2.43 \mu \mathrm{m}$, respectively. Table 10 shows the error percentage for experimental validation of the developed models for the responses with optimal parametric setting. From the analysis it was concluded that the error between experimental and predicted values for MRR, overcut, and surface roughness lies within $6.95 \%, 6.32 \%$, and $7.25 \%$, respectively. Obviously, this confirms excellent reproducibility of the experimental conclusions.

\section{Conclusions}

In the present study, experimental investigation on material transfer mechanism in WEDM of pure titanium (grade 2) was done. Pulse on time, pulse off time, peak current, spark gap voltage, wire feed, and wire tension parameters were used to carry out the experimental study. The following conclusions were drawn.

(1) The residuals of copper, carbon, and zinc were detected in the machined samples using EDX technique. This may be due to the melting, evaporation, and resolidification of the brass wire electrode and are transferred to the work material. XRD pattern analysis confirmed the migration of tool material and dielectric fluid elements on the work surface. The compounds like titanium dioxide (rutile) $\left(\mathrm{TiO}_{2}\right)$, 


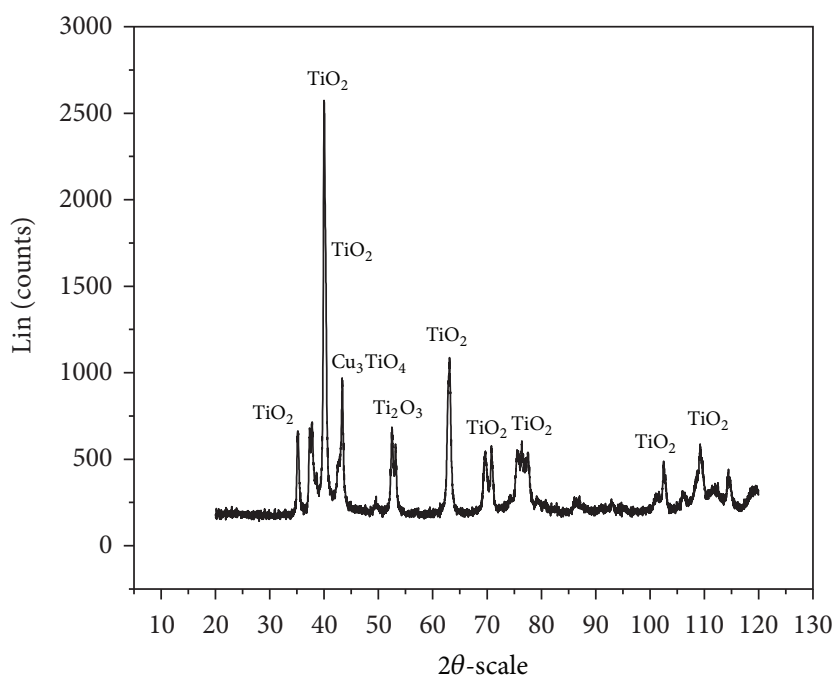

(a)

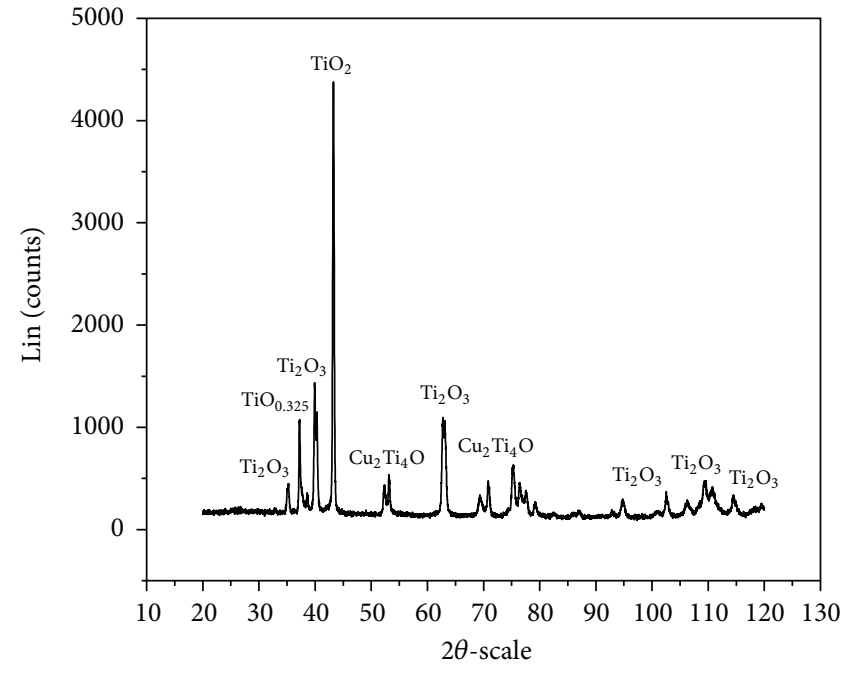

(b)

FIGURE 11: XRD pattern of the machined surface: (a) $T_{\text {on }}=1.1 \mu \mathrm{s}, T_{\text {off }}=28 \mu \mathrm{s}, \mathrm{Ip}=200 \mathrm{~A}, \mathrm{SV}=50 \mathrm{~V}, \mathrm{WF}=7 \mathrm{~m} / \mathrm{min}, \mathrm{WT}=500 \mathrm{grams}$; (b) $T_{\text {on }}$ $=0.7 \mu \mathrm{s}, \mathrm{T}_{\text {off }}=28 \mu \mathrm{s}, \mathrm{Ip}=120 \mathrm{~A}, \mathrm{SV}=50 \mathrm{~V}, \mathrm{WF}=7 \mathrm{~m} / \mathrm{min}, \mathrm{WT}=500$ grams.

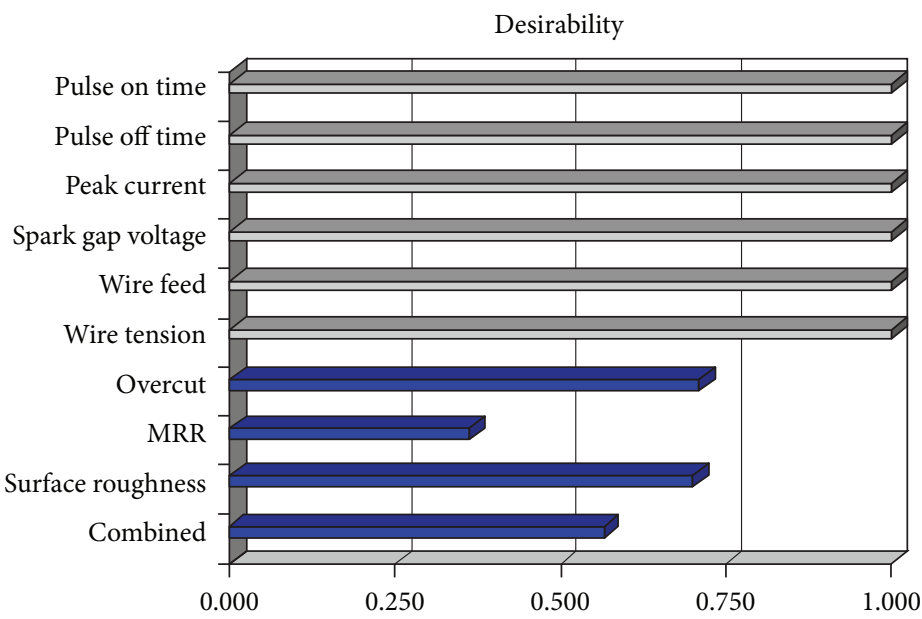

(a)

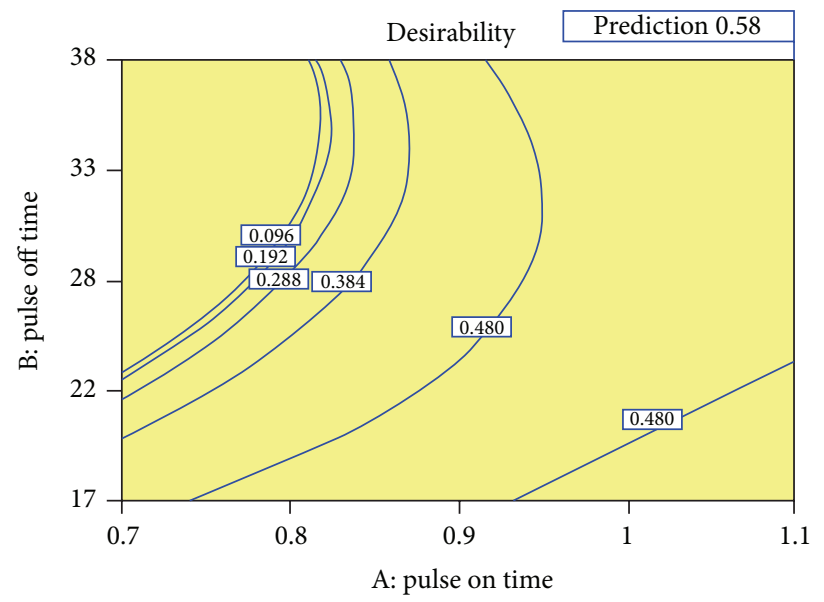

(b)

FIGURE 12: (a) Bar histograms and (b) contour plot for results of overall desirability functions $\left(\right.$ at $T_{\text {on }}=1.1 \mu \mathrm{s}, T_{\text {off }}=38 \mu \mathrm{s}, \mathrm{Ip}=165 \mathrm{~A}, \mathrm{SV}=$ $40 \mathrm{~V}, \mathrm{WF}=4 \mathrm{~m} / \mathrm{min}, \mathrm{WT}=1400$ grams $)$. 
TABLE 8: Process parameters combinations for high value of desirability.

\begin{tabular}{|c|c|c|c|c|c|c|c|c|c|c|}
\hline & & & Factors & & & & & Predict & responses & \\
\hline Exp. no. & $T_{\text {on }}(\mu \mathrm{s})$ & $T_{\text {off }}(\mu \mathrm{s})$ & $\begin{array}{c}\text { Ip } \\
\text { (Ampere) }\end{array}$ & $\begin{array}{c}\text { SV } \\
\text { (Volt) }\end{array}$ & $\begin{array}{c}\mathrm{WF} \\
(\mathrm{m} / \mathrm{min})\end{array}$ & $\begin{array}{c}\text { WT } \\
\text { (grams) }\end{array}$ & $\begin{array}{c}\text { MRR } \\
\left(\mathrm{mm}^{3} / \mathrm{min}\right)\end{array}$ & $\begin{array}{l}\text { Overcut } \\
(\mu \mathrm{m})\end{array}$ & $\begin{array}{l}\text { Surface } \\
\text { roughness } \\
(\mu \mathrm{m})\end{array}$ & Desirability \\
\hline 1 & 1.1 & 38 & 165 & 40 & 4 & 1400 & 7.63 & 29.20 & 2.43 & 0.603 \\
\hline 2 & 1.0 & 38 & 160 & 40 & 4 & 500 & 7.46 & 28.82 & 2.40 & 0.599 \\
\hline 3 & 1.1 & 38 & 151 & 43 & 4 & 500 & 7.14 & 28.11 & 2.44 & 0.589 \\
\hline 4 & 1.0 & 38 & 166 & 46 & 4 & 500 & 7.53 & 29.80 & 2.40 & 0.583 \\
\hline 5 & 1.1 & 33 & 173 & 40 & 4 & 500 & 7.98 & 31.21 & 2.49 & 0.579 \\
\hline 6 & 1.1 & 30 & 154 & 40 & 10 & 1394 & 7.79 & 30.79 & 2.53 & 0.577 \\
\hline 7 & 1.1 & 38 & 144 & 40 & 5 & 1398 & 7.00 & 28.15 & 2.47 & 0.577 \\
\hline 8 & 1.1 & 26 & 151 & 40 & 10 & 500 & 8.47 & 32.40 & 2.47 & 0.577 \\
\hline 9 & 1.1 & 31 & 157 & 40 & 10 & 1393 & 7.79 & 30.81 & 2.39 & 0.576 \\
\hline 10 & 1.0 & 21 & 130 & 40 & 4 & 1400 & 9.19 & 33.79 & 2.47 & 0.574 \\
\hline 11 & 1.0 & 23 & 145 & 40 & 10 & 1400 & 8.87 & 33.28 & 2.37 & 0.573 \\
\hline 12 & 1.1 & 24 & 146 & 40 & 10 & 500 & 8.84 & 33.23 & 2.41 & 0.573 \\
\hline 13 & 0.9 & 21 & 154 & 40 & 4 & 1400 & 8.38 & 32.37 & 2.45 & 0.573 \\
\hline 14 & 1.1 & 26 & 137 & 40 & 10 & 500 & 8.16 & 31.95 & 2.51 & 0.571 \\
\hline 15 & 1.0 & 28 & 154 & 40 & 9 & 505 & 8.08 & 31.89 & 2.44 & 0.568 \\
\hline 16 & 1.1 & 38 & 138 & 43 & 10 & 1400 & 6.78 & 27.87 & 2.43 & 0.566 \\
\hline 17 & 0.9 & 18 & 149 & 40 & 4 & 1400 & 8.69 & 33.27 & 2.48 & 0.564 \\
\hline 18 & 1.1 & 25 & 138 & 40 & 9 & 1400 & 8.41 & 32.76 & 2.45 & 0.563 \\
\hline 19 & 0.9 & 17 & 162 & 40 & 4 & 1400 & 8.84 & 33.74 & 2.45 & 0.558 \\
\hline 20 & 0.9 & 17 & 152 & 40 & 4 & 500 & 8.96 & 34.01 & 2.43 & 0.555 \\
\hline 21 & 1.1 & 38 & 148 & 41 & 4 & 788 & 7.07 & 29.65 & 2.43 & 0.553 \\
\hline 22 & 1.1 & 26 & 142 & 48 & 4 & 1400 & 7.64 & 31.45 & 2.49 & 0.552 \\
\hline 23 & 1.0 & 38 & 156 & 48 & 4 & 1100 & 7.20 & 30.55 & 2.43 & 0.543 \\
\hline 24 & 1.0 & 22 & 148 & 40 & 7 & 500 & 8.55 & 30.97 & 2.53 & 0.536 \\
\hline 25 & 1.0 & 38 & 176 & 58 & 10 & 500 & 6.94 & 30.45 & 2.47 & 0.527 \\
\hline
\end{tabular}

TABLE 9: Multioptimal parametric settings for MRR, overcut, and surface roughness.

\begin{tabular}{lcc}
\hline Parameters & Units & Optimal parameter settings \\
\hline Pulse on time & $\mu \mathrm{s}$ & 1.1 \\
Pulse off time & $\mu \mathrm{s}$ & 38 \\
Peak current & Ampere & 128 \\
Spark gap voltage & Volt & 50 \\
Wire feed & $\mathrm{m} / \mathrm{min}$ & 4 \\
Wire tension & Grams & 1350 \\
\hline
\end{tabular}

$\left(\mathrm{TiO}_{0.325}\right), \mathrm{Ti}_{2} \mathrm{O}_{3}$, Ilmenite $\left(\mathrm{Fe}_{2} \mathrm{Ti}_{4} \mathrm{O}\right)$, and copper titanium dioxide $\left(\mathrm{Cu}_{3} \mathrm{TiO}_{4}\right)$ were formed.

(2) Wire rupturing and wire wear rate were observed due to high peak current and more spark frequency. The formation of craters and the residuals of debris adhered to the surface of wire electrode. The cracks were observed due to high pulse on time and peak current. The crack density was increased due to rapid cooling and heating in the spark zone.

(3) This recast layer was developed due to high peak current. Also the minor cracks were observed that is may be due to high pulse on time and high peak current.

(4) Pulse on time, peak current, and pulse off time were found to be the most significant factors affecting material removal rate. The wire feed and wire tension were found to be insignificant.

(5) The overcut was found to vary from $26.85 \mu \mathrm{m}$ to $34.07 \mu \mathrm{m}$. Meanwhile, the interaction between pulse off time and peak current showed the most significant effect on overcut. The overcut was observed during the decrease of spark gap voltage with value of $25.07 \mu \mathrm{m}$ to $35.87 \mu \mathrm{m}$. 
TABLE 10: Experimental validations of developed models with optimal parameter settings.

\begin{tabular}{lcccc}
\hline Responses & Predicted & Experimental & Error (\%) & Desirability \\
\hline MRR $\left(\mathrm{mm}^{3} / \mathrm{min}\right)$ & 7.63 & 8.20 & 6.95 & 0.588 \\
Overcut $(\mu \mathrm{m})$ & 29.20 & 31.17 & 6.32 & 0.573 \\
Surface roughness $(\mu \mathrm{m})$ & 2.43 & 2.62 & 7.25 & 0.562 \\
\hline
\end{tabular}

(6) The surface roughness varies between $2.48 \mu \mathrm{m}$ and $2.62 \mu \mathrm{m}$. The surface roughness was mainly affected by interaction between pulse on time and peak current which ranged between 2.41 and $2.72 \mu \mathrm{m}$.

(7) It was observed that pulse on time and peak current deteriorate the integrity of machined samples which produces the deeper and wider overlapping craters, pockmarks, globules of debris, and microcracks.

\section{References}

[1] S. Y. Hong, I. Markus, and W.-C. Jeong, "New cooling approach and tool life improvement in cryogenic machining of titanium alloy Ti-6Al-4V,' International Journal of Machine Tools and Manufacture, vol. 41, no. 15, pp. 2245-2260, 2001.

[2] A. B. Puri and B. Bhattacharyya, "An analysis and optimisation of the geometrical inaccuracy due to wire lag phenomenon in WEDM," International Journal of Machine Tools and Manufacture, vol. 43, no. 2, pp. 151-159, 2003.

[3] K. H. Ho, S. T. Newman, S. Rahimifard, and R. D. Allen, "State of the art in wire electrical discharge machining (WEDM)," International Journal of Machine Tools and Manufacture, vol. 44, no. 12-13, pp. 1247-1259, 2004.

[4] E. O. Ezugwu and Z. M. Wang, "Titanium alloys and their machinability—a review," Journal of Materials Processing Technology, vol. 68, no. 3, pp. 262-274, 1997.

[5] S. F. Miller, A. J. Shih, and J. Qu, "Investigation of the spark cycle on material removal rate in wire electrical discharge machining of advanced materials," International Journal of Machine Tools and Manufacture, vol. 44, no. 4, pp. 391-400, 2004.

[6] J. T. Huang and Y. S. Liao, "Optimization of machining parameters of Wire-EDM based on Grey relational and statistical analyses," International Journal of Production Research, vol. 41, no. 8, pp. 1707-1720, 2003.

[7] M. S. Hewidy, T. A. El-Taweel, and M. F. El-Safty, "Modelling the machining parameters of wire electrical discharge machining of Inconel 601 using RSM," Journal of Materials Processing Technology, vol. 169, no. 2, pp. 328-336, 2005.

[8] S. S. Mahapatra and A. Patnaik, "Optimization of wire electrical discharge machining (WEDM) process parameters using Taguchi method," International Journal of Advanced Manufacturing Technology, vol. 34, no. 9-10, pp. 911-925, 2007.

[9] R. Ramakrishnan and L. Karunamoorthy, "Multi response optimization of wire EDM operations using robust design of experiments," International Journal of Advanced Manufacturing Technology, vol. 29, no. 1-2, pp. 105-112, 2006.

[10] A. Manna and B. Bhattacharyya, "Taguchi and Gauss elimination method: a dual response approach for parametric optimization of CNC wire cut EDM of PRAlSiCMMC," International Journal of Advanced Manufacturing Technology, vol. 28, no. 1-2, pp. $67-75,2006$.
[11] S. Sarkar, S. Mitra, and B. Bhattacharyya, "Parametric optimisation of wire electrical discharge machining of $\gamma$ titanium aluminide alloy through an artificial neural network model," International Journal of Advanced Manufacturing Technology, vol. 27, no. 5-6, pp. 501-508, 2006.

[12] S. Sarkar, K. Ghosh, S. Mitra, and B. Bhattacharyya, "An integrated approach to optimization of WEDM combining singlepass and multipass cutting operation," Materials and Manufacturing Processes, vol. 25, no. 8, pp. 799-807, 2010.

[13] R. T. Yang, C. J. Tzeng, Y. K. Yang, and M. H. Hsieh, “Optimization of wire electrical discharge machining process parameters for cutting tungsten," International Journal of Advanced Manufacturing Technology, vol. 60, no. 1-4, pp. 135-147, 2012.

[14] A. Kumar, V. Kumar, and J. Kumar, "An investigation into machining characteristics of commercially pure titanium (Grade-2) using CNC WEDM," Applied Mechanics and Materials, vol. 159, pp. 56-68, 2012.

[15] A. Shah, N. A. Mufti, D. Rakwal, and E. Bamberg, "Material removal rate, kerf, and surface roughness of tungsten carbide machined with wire electrical discharge machining," Journal of Materials Engineering and Performance, vol. 20, no. 1, pp. 71-76, 2011.

[16] M. Sadeghi, H. Razavi, A. Esmaeilzadeh, and F. Kolahan, "Optimization of cutting conditions in WEDM process using regression modelling and Tabu-search algorithm," Proceedings of the Institution of Mechanical Engineers B, vol. 225, no. 10, pp. 18251834, 2011.

[17] K.-Y. Kung and K.-T. Chiang, "Modeling and analysis of machinability evaluation in the wire electrical discharge machining (WEDM) process of aluminum oxide-based ceramic," Materials and Manufacturing Processes, vol. 23, no. 3, pp. 241-250, 2008.

[18] C.-J. Tzeng, Y.-K. Yang, M.-H. Hsieh, and M.-C. Jeng, "Optimization of wire electrical discharge machining of pure tungsten using neural network and response surface methodologyg," Proceedings of the Institution of Mechanical Engineers B, vol. 225, no. 6, pp. 841-852, 2011.

[19] R. V. Rao and P. J. Pawar, "Modelling and optimization of process parameters of wire electrical discharge machining," Proceedings of the Institution of Mechanical Engineers B, vol. 223, no. 11, pp. 1431-1440, 2009.

[20] P.-H. Yu, H.-K. Lee, Y.-X. Lin, S.-J. Qin, B.-H. Yan, and F.-Y. Huang, "Machining characteristics of polycrystalline silicon by wire electrical discharge machining," Materials and Manufacturing Processes, vol. 26, no. 12, pp. 1443-1450, 2011.

[21] N. Kuruvila and H. V. Ravindra, "Parametric influence and optimization of wire edm of hot die steel," Machining Science and Technology, vol. 15, no. 1, pp. 47-75, 2011.

[22] S. H. Lee and X. Li, "Study of the surface integrity of the machined workpiece in the EDM of tungsten carbide," Journal of Materials Processing Technology, vol. 139, no. 1-3, pp. 315-321, 2003.

[23] Y.-C. Lin, Y.-F. Chen, C.-T. Lin, and H.-J. Tzeng, "Electrical Discharge Machining (EDM) characteristics associated with 
electrical discharge energy on machining of cemented tungsten carbide," Materials and Manufacturing Processes, vol. 23, no. 4, pp. 391-399, 2008.

[24] K. P. Somashekhar, N. Ramachandran, and J. Mathew, "Material removal characteristics of microslot (kerf) geometry in $\mu$ WEDM on aluminum," International Journal of Advanced Manufacturing Technology, vol. 51, no. 5-8, pp. 611-626, 2010.

[25] Y.-C. Lin, C.-H. Cheng, B.-L. Su, and L.-R. Hwang, "Machining characteristics and optimization of machining parameters of SKH 57 high-speed steel using electrical-discharge machining based on Taguchi method," Materials and Manufacturing Processes, vol. 21, no. 8, pp. 922-929, 2006.

[26] S. H. Lee and X. Li, "Study of the surface integrity of the machined workpiece in the EDM of tungstencarbide," Journal of Materials Processing Technology, vol. 139, no. 1-3, pp. 315-321, 2003.

[27] A. Kumar, S. Maheshwari, C. Sharma, and N. Beri, "Research developments in additives mixed electrical discharge machining (AEDM): a state of art review," Materials and Manufacturing Processes, vol. 25, no. 10, pp. 1166-1180, 2010.

[28] H. T. Lee and T. Y. Tai, "Relationship between EDM parameters and surface crack formation," Journal of Materials Processing Technology, vol. 142, no. 3, pp. 676-683, 2003.

[29] A. Hasçalik and U. Çaydaş, "Electrical discharge machining of titanium alloy (Ti-6Al-4V)," Applied Surface Science, vol. 253, no. 22, pp. 9007-9016, 2007.

[30] N. G. Patil and P. K. Brahmankar, "Some studies into wire electro-discharge machining of alumina particulate-reinforced aluminum matrix composites," International Journal of Advanced Manufacturing Technology, vol. 48, no. 5-8, pp. 537-555, 2010.

[31] D. C. Montgomery, Design and Analysis of Experiments, Wiley, New York, NY, USA, 5th edition, 2001. 

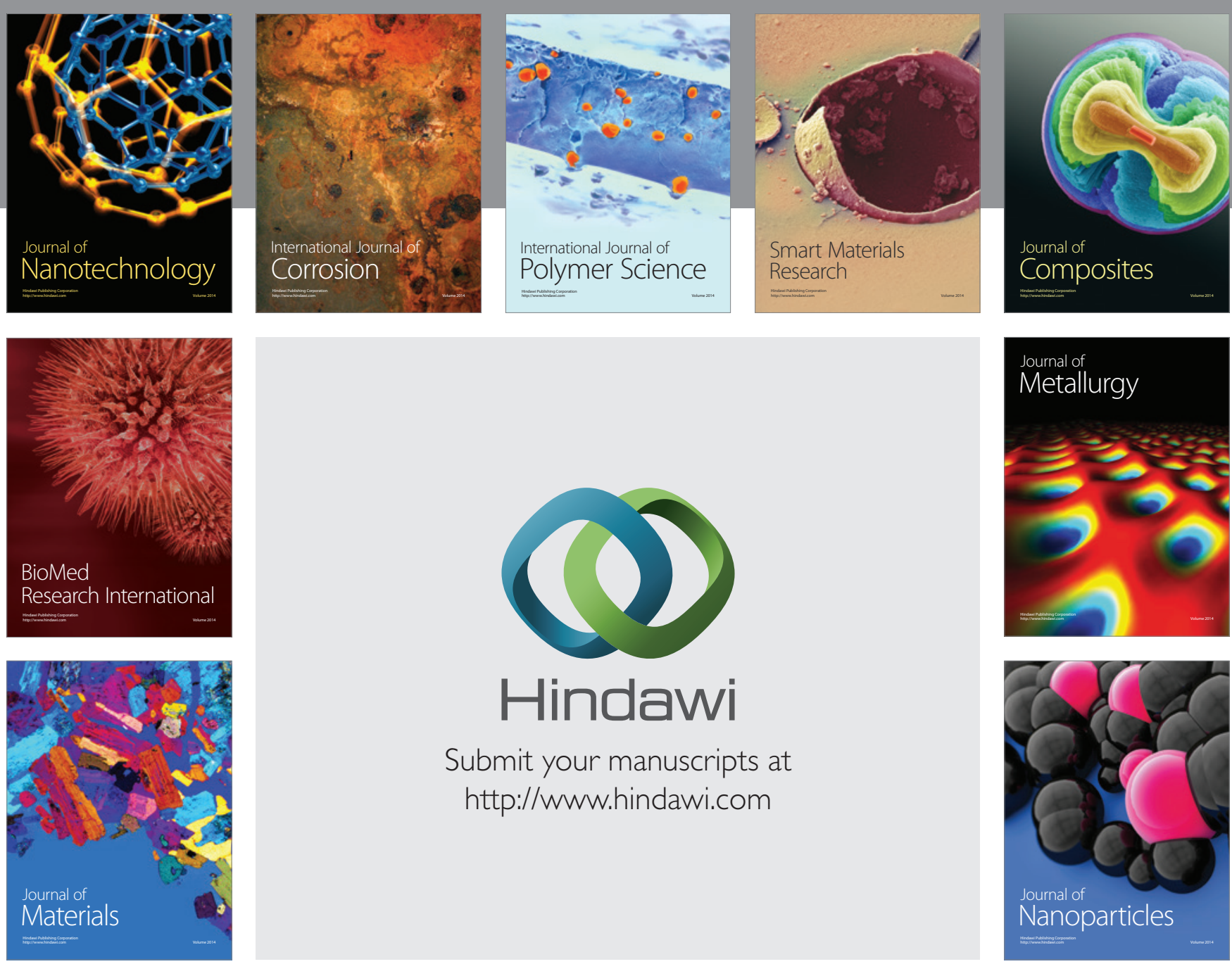

Submit your manuscripts at http://www.hindawi.com
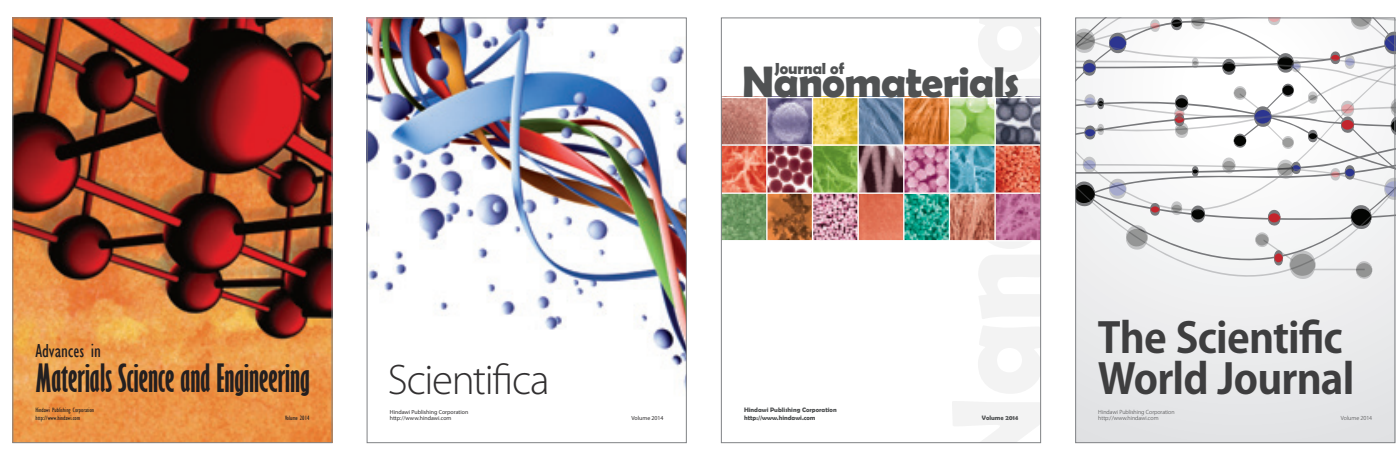

\section{The Scientific World Journal}
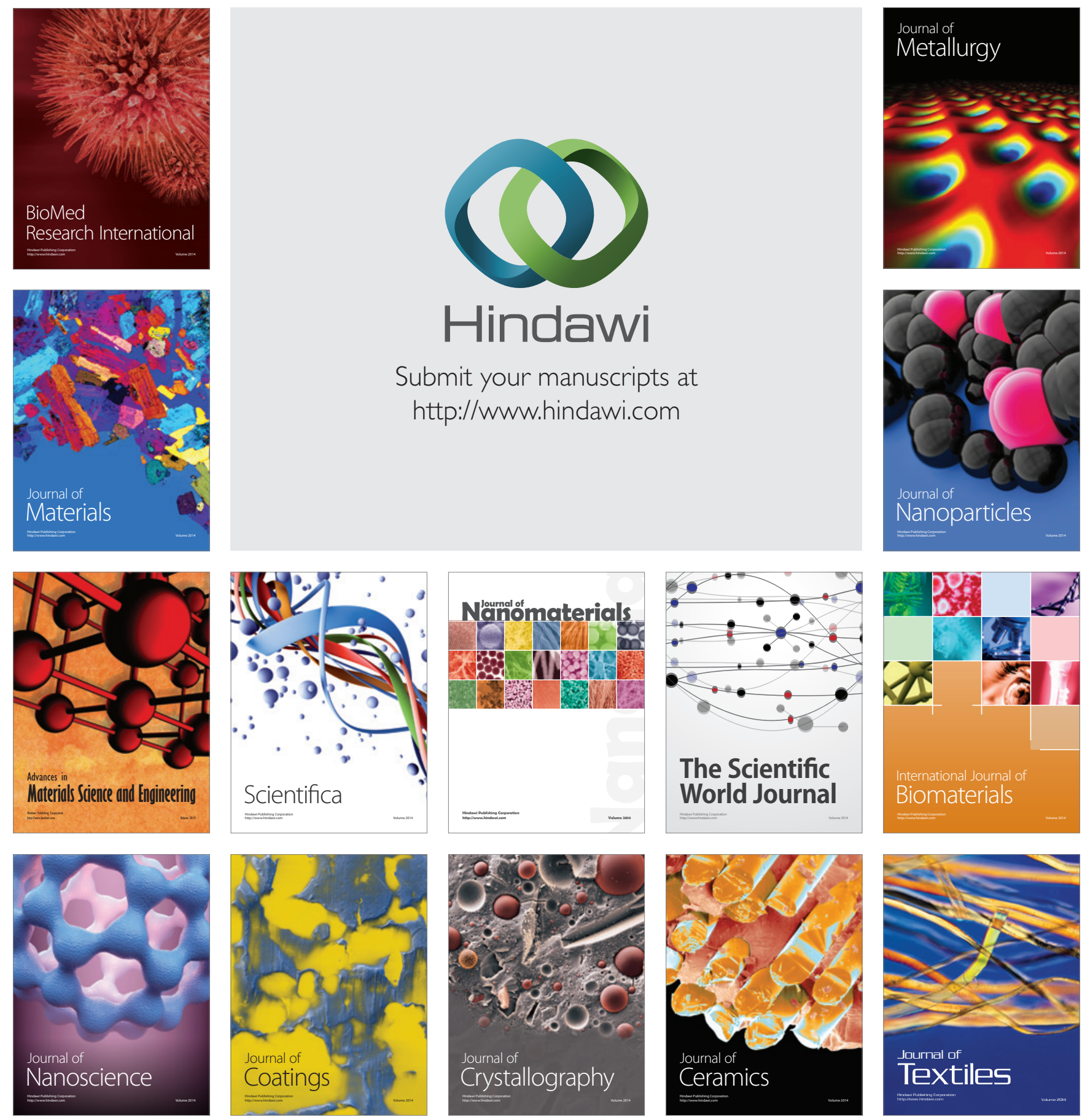